\title{
Strong conceptual ability reduces the effect of lexical impairments on verb retrieval in aphasia
}

Running title: Variability in aphasic verb retrieval

\author{
Haley C. Dresang ${ }^{a, b^{*}}$, William D. Hula ${ }^{c, d}$, Tessa Warren ${ }^{d}, \&$ Michael Walsh Dickey ${ }^{d, c}$ \\ a Department of Neurology, University of Pennsylvania, Philadelphia, Pennsylvania, United \\ States of America \\ ${ }^{\mathrm{b}}$ Moss Rehabilitation Research Institute, Philadelphia, Pennsylvania, United States of America \\ ${ }^{c}$ VA Pittsburgh Healthcare System, Pittsburgh, Pennsylvania, United States of America \\ ${ }^{\mathrm{d}}$ Department of Communication Science \& Disorders, University of Pittsburgh, Pittsburgh, \\ Pennsylvania, United States of America \\ e Learning Research \& Development Center, Department of Psychology, University of \\ Pittsburgh, Pittsburgh, Pennsylvania, United States of America
}

* Correspondence: Haley C. Dresang, Ph.D., DresangH@Einstein.edu

Keywords: aphasia, verb retrieval, conceptual action-processing, lexical action-processing. 


\begin{abstract}
Verb-retrieval impairments are pervasive deficits that can negatively impact communicative function for individuals living with aphasia. Unfortunately, the neurocognitive basis of these deficits remains poorly understood. One open question is the degree to which verbretrieval impairments might be rooted in lexical- versus conceptual-processing deficits. These deficits can be co-present and correlated in people with aphasia, but they have also been found to be dissociated in patients with a variety of acquired brain injuries. This study examined the degree to which conceptual versus lexical action-processing abilities are impaired and may contribute to verb-retrieval impairments in adults with chronic aphasia due to left-hemisphere stroke. The results indicate that conceptual action processing can be impaired in aphasia and may contribute to verb-retrieval impairments. Furthermore, relatively unimpaired conceptual processing can ameliorate the influence of lexical impairments on verb-retrieval impairments. These findings are consistent with models in which conceptual representations play a key role in language processing and may be leveraged to improve verb retrieval in adults with chronic aphasia.
\end{abstract}

\title{
Highlights
}

- Conceptual and lexical deficits both contribute to aphasic verb-naming impairments.

- Conceptual deficits are more predictive of verb naming than lexical deficits are.

- Stronger conceptual processing reduces lexical-deficit effects on verb-naming. 


\section{Introduction}

Verb-retrieval impairments are common in both stroke and neurodegenerative disorders and can have significant negative impact on everyday communicative function (Bak, 2013; Rofes et al., 2015). There is substantial evidence that both linguistic and conceptual processing contribute to verb retrieval in healthy adults and likely in adults with aphasia as well (Dresang et al., 2019; McRae \& Matsuki, 2009; Vigliocco et al., 2011; see discussion below). The objective of this study was to characterize how linguistic and conceptual deficits each contribute to verbretrieval impairments in aphasia. This is important because doing so can shed light on the cognitive systems that support verb retrieval and underlie their impairments. It also may inform strategies to focus on linguistic versus conceptual treatments in patients with verb-retrieval impairments.

There is significant evidence that linguistic deficits contribute to verb-retrieval impairments. Neuropsychological research on verb-retrieval impairments has historically focused on demonstrating dissociations between noun and verb retrieval in individuals with both stroke aphasia (Bastiaanse \& Jonkers, 1998; Caramazza \& Hillis, 1991; Kim \& Thompson, 2000) and primary progressive aphasia (Thompson et al., 2012), as well as individuals with other neurological conditions, such as frontotemporal dementia (Bak \& Hodges, 2003) and motor neuron disease (Bak \& Chandran, 2012). These findings suggest that word-retrieval impairments are sensitive to grammatical class differences. However, complementary work has demonstrated not only that verbs may be more impaired than nouns for neurologically-impaired individuals (Mätzig et al., 2009) but that the linguistic properties of verbs may critically influence verbretrieval impairments. For example, both syntactic features like argument structure (Malyutina et al., 2016; Shapiro \& Levine, 1990; Thompson, 2003) and lexical-semantic properties such as 
semantic weight (Barde et al., 2006; Gordon \& Dell, 2003; Kim \& Thompson, 2004) contribute to patterns of verb impairments. For instance, individuals with Alzheimer's disease exhibit greater difficulty with retrieval of semantically heavy verbs (Kim \& Thompson, 2004), whereas individuals with agrammatic aphasia exhibit greater retrieval impairments for light verbs (Gordon \& Dell, 2003; Thorne \& Faroqi-Shah, 2016) and verbs with more complex argument structure (Cho-Reyes \& Thompson, 2012; Thompson, 2003). These findings suggest that linguistic factors may be useful in characterizing verb-retrieval impairments in aphasia and other neurological conditions, and they help motivate aphasia treatment approaches that target linguistic representations to ameliorate verb-retrieval impairments (Links et al., 2010; Thompson $\&$ Shapiro, 2005).

There is a parallel body of evidence that conceptual representations and deficits also contribute to verb-retrieval. Psycholinguistic studies in neurotypical adults have demonstrated that conceptual representations are engaged during verb retrieval. When neurotypical adults retrieve verbs, they automatically activate event concepts: sets of commonly co-occurring actions, objects, people, and settings (McRae \& Matsuki, 2009); these activated event concepts facilitate retrieval of nouns describing people and objects that participate in those events (McRae et al., 2005). This relationship is bidirectional, such that nouns describing these event participants also facilitate retrieval of conceptually-related verbs (McRae et al., 2005). Eventconcept activation by verbs facilitates both sentence and discourse comprehension in healthy adults (Elman \& McRae, 2019; Zwaan, 2015) and is furthermore the hypothesized mechanism underlying several efficacious aphasia therapies (such as Verb Network Strengthening Treatment [VNeST]: Edmonds, 2016, and Verb as Core: Loverso et al., 1988). 
In addition, neuroimaging and neuropsychological studies have demonstrated that verbs automatically activate action concepts and features, including motor features. Verbs activate motor and pre-motor cortex in both functional neuroimaging (Hauk et al., 2004) and electocorticography studies (Yang et al., 2017), even when those verbs are used non-literally (e.g., grasp an idea, Boulenger et al., 2009). Neurostimulation to motor and pre-motor regions can also facilitate (Pulvermüller et al., 2005) or disrupt action-related semantic processing (Gerfo et al., 2008), and can facilitate novel action-word learning (Liuzzi et al., 2010). Conceptual and motor representations also play a key role in characterizing verb-retrieval impairments in neurologically impaired populations. For example, individuals with neurodegenerative diseases affecting primary motor and premotor cortex show significant correlations between degree of atrophy and impairments of both action knowledge and verb retrieval (Bak, 2013; Roberts et al., 2017). Similarly, lesion to pre-motor cortex after acquired brain injury has been associated with both action- and verb-processing impairments (Kemmerer et al., 2012), and the integrity of corticosubcortical projection pathways implicated in motor functions predicts verb-retrieval ability in adults with and without aphasia (Dresang, Hula, et al., 2021). These findings underline the importance of conceptual-motor representations in characterizing verb-retrieval ability. They also help motivate aphasia treatment approaches that leverage action concepts to improve verb retrieval (such as gesture-based treatments, e.g., Rose \& Sussmilch, 2008; and Semantic Feature Analysis for actions: Wambaugh et al., 2014).

Despite this evidence, it remains unclear how linguistic and conceptual deficits each contribute to verb-retrieval impairments in individuals with aphasia, a population in which verbretrieval impairments are especially prominent (Mätzig et al., 2009; Rofes et al., 2015). However, we know slightly more about the related question: what is the relationship between 
linguistic and conceptual deficits in post-stroke populations? Some studies have reported dissociations between conceptual and linguistic processing, using carefully matched assessment measures that employ parallel stimuli in action/event-processing and verb processing tasks. For instance, in a large sample of individuals with a variety of acquired brain injuries, Kemmerer and colleagues (2012) found that across participants there were widely varying patterns of associations and dissociations across six standardized assessments of linguistic and conceptual verb/action processing (Fiez \& Tranel, 1997; Kemmerer et al., 2012). In a separate study of adults with aphasia, Saygin and colleagues (2004) found that participants with severe and nonfluent aphasia profiles showed greater impairment on linguistic verb-processing tasks compared to matched conceptual action-processing tasks. These findings suggest that verb and action processing deficits may be dissociated post-stroke.

In contrast, other findings suggest that conceptual action and linguistic verb deficits are associated in post-stroke populations. For example, in the same study reported above, Saygin and colleagues (2004) found that relatively mild and fluent participants with aphasia showed robust correlations between linguistic verb-processing task performance and conceptual actionprocessing task performance. Similarly, Dresang and colleagues (Dresang et al., 2019) found that the degree of conceptual-processing deficits for actions and events predicted verb-processing impairments in adults with aphasia. In particular, verb production impairments were associated with event-processing deficits and verb comprehension impairments were associated with actionprocessing deficits. In a separate priming study, Dresang and colleagues (2021) found that noun primes describing event-related concepts facilitated verb retrieval, leading to more accurate verb naming for people with aphasia as well as a sample of healthy age-matched controls. These studies suggest a close association between linguistic (verb) and conceptual (event and action) 
representations in post-stroke populations, and even provide some evidence that verb retrieval might be influenced by conceptual impairment. However, these studies generally did not disentangle verb retrieval from other aspects of verb processing and thus leave open the question of whether deficits in these other aspects of verb processing (or other linguistic processing) might interact with conceptual deficits to contribute to verb retrieval impairments

It thus remains unclear how linguistic and conceptual deficits are related and whether they might interact to predict verb-retrieval impairments in aphasia. There are at least two hypotheses regarding how these deficits might contribute to verb-retrieval impairments. The first hypothesis is that linguistic deficits are the primary drivers, or predictors, of verb-retrieval impairments in aphasia. This hypothesis is motivated by the significant evidence suggesting that linguistic representations and specific linguistic deficits play a critical role in characterizing verb-retrieval impairments in aphasia and other neurological disorders (Barde et al., 2006; Gordon \& Dell, 2003; Malyutina et al., 2016; Thompson, 2003). It is also consistent with findings that linguistic and conceptual processing may be dissociated post-stroke (Kemmerer et al., 2012) and in aphasia (Saygin et al., 2004). The second hypothesis is that the degree of both conceptual and linguistic deficits are key predictors of verb-retrieval impairments in aphasia. This hypothesis is motivated by evidence that event-related noun concepts can facilitate verb retrieval in both neurotypical adults (McRae \& Matsuki, 2009) and adults with aphasia (Dresang, Warren, et al., 2021). It is also consistent with the findings suggesting that verb retrieval and conceptual processing may be correlated in aphasia (Dresang et al., 2019; Saygin et al., 2004). To address these competing hypotheses, the current study relates verb-retrieval ability on picture-naming scores of adults with and without aphasia to performance on a standardized battery of linguistic/verb-based versus conceptual/picture-based action-processing. 


\section{Methods}

\subsection{Participants}

Participants were 17 individuals with chronic aphasia due to unilateral left hemisphere stroke and 15 age-matched neurotypical controls. All participants were 1) native English speakers, 2) able to provide informed consent, 3) 42-78 years old, 4) (pre-morbidly) righthanded, 5) had no significant hearing loss or vision impairment that prevented them from completing the experimental tasks, 6) had no pre-existing or subsequent brain injury/stroke (e.g., to right-hemisphere regions for individuals with aphasia), and 7) had no history of progressive neurological or psychiatric disease, drug, or alcohol dependence, or significant mood or behavioral disorder. In addition, all neurotypical participants passed a line-bisection visual screening, a binaural pure-tone hearing screening $(0.5,1,2$, and $4 \mathrm{KHz}$ at $40 \mathrm{~dB})$, a Mini-Mental State Examination cognitive screen (required 27/30; Folstein et al., 1975), and Raven's Coloured Progressive Matrices non-linguistic cognitive screen (required 30/36; Raven, 1965).

All participants with aphasia were more than 6 months post-onset (range: 19-265 months; $\mathrm{M}=95.8, \mathrm{SD}=62$ months), had a Comprehensive Aphasia Test (CAT; (Swinburn et al., 2004) Naming Modality T-score $\geq 40$, Cognitive Screening for recognition memory T-score $\geq 30$, and an overall mean T-score $<70$. Cognitive screening and general language assessment measures, including the CAT, were already available for the participants with aphasia, who had recently participated in Hula and colleagues' study (Hula et al., 2020). Institutional Review Board approval was obtained, and all participants provided informed written consent and were compensated for their time. Demographic participant characteristics are reported in Table 1 for participants with aphasia and Table 2 for age-matched controls.

Table 1. Demographic characteristics of participants with aphasia 


\begin{tabular}{ccccccc}
\hline $\begin{array}{c}\text { Participant } \\
\text { ID }\end{array}$ & Age & Sex & Education Level & $\begin{array}{c}\text { Years of } \\
\text { Education }\end{array}$ & $\begin{array}{c}\text { Months } \\
\text { Post-Onset }\end{array}$ & $\begin{array}{c}\text { Years } \\
\text { Post-Onset }\end{array}$ \\
\hline 7201 & 59 & F & Graduate degree & 20 & 132 & 11 \\
7202 & 63 & M & Bachelor's degree & 14 & 265 & 22.08 \\
7203 & 61 & F & Master's degree & 17 & 60 & 5 \\
7204 & 55 & M & High school & 12 & 53 & 4.42 \\
7205 & 52 & M & High school & 12 & 136 & 11.33 \\
7206 & 78 & F & Some graduate & 13 & 114 & 9.5 \\
7207 & 70 & F & Some college & 14 & 45 & 3.75 \\
7208 & 76 & M & Some college & 14 & 138 & 11.5 \\
7209 & 77 & M & Law degree & 19 & 53 & 4.42 \\
7210 & 54 & M & Bachelor's degree & 16 & 83 & 6.92 \\
7211 & 71 & M & Some college & 14 & 26 & 2.17 \\
7212 & 55 & M & Bachelor's degree & 16 & 19 & 1.58 \\
7213 & 68 & M & High school & 12 & 184 & 15.33 \\
7214 & 53 & F & Bachelor's degree & 17 & 81 & 6.75 \\
7215 & 71 & M & Bachelor's degree & 16 & 87 & 7.25 \\
7216 & 72 & M & Some college & 14 & 60 & 5 \\
7217 & 72 & M & Some college & 15 & 93 & 7.75 \\
\hline Summary & M=65.12 & 5 F; & & M=15 & M=95.82 & M=7.99 \\
& SD=9.11 & 12 M & & SD=2.35 & SD=62 & SD=5.17 \\
\hline
\end{tabular}

Table 2. Demographic characteristics of age-matched control participants

\begin{tabular}{ccccc}
\hline Participant ID & Age & Sex & Education Level & Years of Education \\
\hline 7001 & 42 & M & Tech college & 14.5 \\
7002 & 59 & M & High school & 12 \\
7003 & 74 & M & Bachelor's degree & 16 \\
7004 & 52 & M & Bachelor's degree & 16 \\
7005 & 54 & M & Bachelor's degree & 16 \\
7006 & 57 & M & High school & 12 \\
7007 & 72 & F & Master's degree & 18 \\
7008 & 64 & F & Master's degree & 18 \\
7010 & 74 & M & Master's degree & 20 \\
7011 & 68 & F & Master's degree & 22 \\
7012 & 72 & M & Bachelor's degree & 16 \\
7013 & 65 & M & Law degree & 19 \\
7014 & 71 & F & Master's degree & 17 \\
7015 & 52 & M & Master's degree & 22 \\
7016 & 69 & F & Master's degree & 18 \\
\hline
\end{tabular}




$\begin{array}{cccc}\text { Summary } & \mathrm{M}=63 & 5 \mathrm{~F} ; 10 \mathrm{M} & \mathrm{M}=17.1 \\ & \mathrm{SD}=9.82 & & \mathrm{SD}=3\end{array}$

\subsection{Materials}

All participants completed a set of behavioral language and conceptual knowledge assessments to test verb and action processing. A standardized action knowledge battery (Fiez \& Tranel, 1997) was used to probe participants' abilities to retrieve lexical and conceptual information pertaining to actions. The action knowledge battery consisted of (1) a verb retrieval task (action naming), (2) two conceptual, picture-based tasks (picture attribute and picture comparison judgments), and (3) two linguistic, verb-based tasks (word attribute and word comparison judgments). See section 2.3 and Fiez and Tranel (1997) for task details. These tasks provide: a measure of verb retrieval via action naming, and a comprehensive and detailed classification of linguistic versus conceptual verb and action impairments via the matched conceptual and linguistic tasks. These will henceforth be referred to as lexical versus conceptual action-processing abilities and impairments.

\subsection{Testing procedure}

The full battery of tasks was presented on a computer monitor, in the same order presented by Kemmerer and colleagues (2012): Naming, Picture Comparison, Picture Attribute, Word Comparison, and Word Attribute. Participants were given detailed instructions and practice items to ensure they understood each task. Brief descriptions of the tasks are provided below. Further details are reported in Fiez and Tranel (1997) and Kemmerer, Tranel, and Barrash (2001). For a summary of previous studies that have used tests from this battery, see Kemmerer and colleagues (2012). Participants viewed stimuli on computer screen. They were allowed an 
unlimited amount of time to respond to each item. An external microphone recorded naming responses using Audacity ${ }^{\circledR}$ software, and trial-level accuracy was scored by hand for each task.

Naming Task ( $\mathrm{N}=100$ items): For each item, the participant was shown a single colored photograph of a person or animal performing an action. The participant was instructed to provide a single word/verb that describes what the person or animal was doing. The participant's first response was recorded. Following Fiez and Tranel (1997), experimenters prompted participants for a second response if the participant did not provide a verb (e.g. "Can you tell me what the person is doing?") or if the participant provided a description (e.g. "Can you give me a single word that best describes what the person is doing?"). Target responses provided after a prompt were also scored as correct. Alternate forms of a target verb were accepted as correct (e.g. run, running, ran). Normative data (from Fiez \& Tranel, 1997): $M=85.0 \%$ correct; SD = 5.0.

Picture Comparison Task $(\mathrm{N}=24$ items): For each item, the participant was shown three colored photographs depicting actions. The participant was instructed to determine which picture showed an action that was most different in meaning from the other two (e.g. cutting a pie, cutting a piece of paper, folding a piece of paper). This task is analogous to the Word Comparison Task. Normative data (from Fiez \& Tranel, 1997): $M=83.6 \%$ correct; $S D=8.3$.

Picture Attribute Task $(\mathrm{N}=72$ items): For each item, the participant was shown two colored photographs depicting actions and an attribute judgment question. The experimenter read the question aloud. The participant was instructed to indicate which picture best answered the question (e.g., "Which action would make the loudest sound?"). This task is analogous to the Word Attribute Task. Normative data (from Fiez \& Tranel, 1997): M =91.7\% correct; SD = 4.8.

Word Comparison Task $(\mathrm{N}=44$ items): For each item, the participant was shown three printed verbs. The experimenter read the verbs aloud. The participant was instructed to 
determine which word was most different in meaning from the other two. This task is analogous to the Picture Comparison Task. Normative data (from Fiez \& Tranel, 1997): $\mathrm{M}=88.7 \%$ correct; $\mathrm{SD}=8.1$

Word Attribute Task $(\mathrm{N}=62$ items): For each item, the participant was shown two printed verbs and an attribute judgment question. The experimenter read the question and the verbs aloud. The participant was instructed to indicate which verb best answered the question (e.g., "Which action would make the loudest sound?"). This task is analogous to the Picture Attribute Task. Normative data (from Fiez \& Tranel, 1997): $\mathrm{M}=94.8 \%$ correct; $\mathrm{SD}=2.6$.

Participant performance on each task is reported in Table 3 for participants with aphasia and Table 4 for age-matched controls.

Table 3. Conceptual and lexical action-processing performance (percent accuracy) for participants with aphasia

\begin{tabular}{ccccccc}
\hline \multirow{2}{*}{$\begin{array}{c}\text { Participant } \\
\text { ID }\end{array}$} & $\begin{array}{c}\text { Action } \\
\text { Naming }\end{array}$ & $\begin{array}{c}\text { Conceptual Action-Processing } \\
\text { Comparison }\end{array}$ & $\begin{array}{c}\text { Picture } \\
\text { Attribute }\end{array}$ & $\begin{array}{c}\text { Loxical Action-Processing } \\
\text { Comparison }\end{array}$ & $\begin{array}{c}\text { Cord } \\
\text { Attribute }\end{array}$ & $\begin{array}{c}\text { Codality } \\
\text { Mean T } \\
\text { Score }\end{array}$ \\
\hline 7201 & 0.63 & 0.88 & 0.93 & 0.80 & 0.82 & 56.33 \\
7202 & 0.31 & 0.58 & 0.58 & 0.34 & 0.53 & 47.83 \\
7203 & 0.56 & 0.50 & 0.83 & 0.70 & 0.92 & 59.67 \\
7204 & 0.77 & 0.79 & 0.86 & 0.75 & 0.84 & 56 \\
7205 & 0.44 & 0.29 & 0.85 & 0.73 & 0.84 & 48.33 \\
7206 & 0.89 & 0.63 & 0.89 & 0.86 & 0.94 & 66.67 \\
7207 & 0.52 & 0.33 & 0.76 & 0.77 & 0.97 & 59 \\
7208 & 0.13 & 0.25 & 0.69 & 0.39 & 0.60 & 47.83 \\
7209 & 0.51 & 0.33 & 0.85 & 0.75 & 0.81 & 52.83 \\
7210 & 0.59 & 0.75 & 0.81 & 0.34 & 0.73 & 51.33 \\
7211 & 0.67 & 0.46 & 0.79 & 0.59 & 0.69 & 50.33 \\
7212 & 0.53 & 0.92 & 0.88 & 0.77 & 0.81 & 51.17 \\
7213 & 0.43 & 0.63 & 0.78 & 0.64 & 0.76 & 49.83 \\
7214 & 0.67 & 0.54 & 0.86 & 0.57 & 0.90 & 62 \\
7215 & 0.02 & 0.29 & 0.64 & 0.48 & 0.56 & 53.17 \\
\hline
\end{tabular}




\begin{tabular}{ccccccc}
\hline 7216 & 0.35 & 0.54 & 0.86 & 0.70 & 0.82 & 42.5 \\
7217 & 0.44 & 0.46 & 0.74 & 0.68 & 0.94 & 58.67 \\
\hline $\mathrm{M}$ & 0.50 & 0.54 & 0.80 & 0.64 & 0.79 & 53.73 \\
$\mathrm{SD}$ & 0.22 & 0.21 & 0.09 & 0.16 & 0.13 & 6.13 \\
\hline
\end{tabular}

Notes: CAT $=$ The Comprehensive Aphasia Test (Swinburn et al., 2004) assesses aphasia severity. All other measures come from the verb and action processing battery (Fiez \& Tranel, 1997).

Table 4. Conceptual and lexical action-processing performance (percent accuracy) for age-matched controls

\begin{tabular}{cccccc}
\hline \multirow{2}{*}{$\begin{array}{c}\text { Participant } \\
\text { ID }\end{array}$} & $\begin{array}{c}\text { Action } \\
\text { Naming }\end{array}$ & $\begin{array}{c}\text { Conceptual Action-Processing } \\
\text { Comparison }\end{array}$ & $\begin{array}{c}\text { Lexical Action-Processing } \\
\text { Attribute }\end{array}$ & $\begin{array}{c}\text { Word } \\
\text { Comparison }\end{array}$ & $\begin{array}{c}\text { Word } \\
\text { Attribute }\end{array}$ \\
\cline { 3 - 5 } 7001 & 0.9 & 0.96 & 0.94 & 0.93 & 0.97 \\
7002 & 0.99 & 0.83 & 0.90 & 0.95 & 0.98 \\
7003 & 0.9 & 0.92 & 0.92 & 0.86 & 0.94 \\
7004 & 0.86 & 0.75 & 0.96 & 0.98 & 0.92 \\
7005 & 0.94 & 0.88 & 0.93 & 0.80 & 0.98 \\
7006 & 0.8 & 0.63 & 0.82 & 0.84 & 0.92 \\
7007 & 0.92 & 0.92 & 0.94 & 0.95 & 0.94 \\
7008 & 0.95 & 0.92 & 0.99 & 1 & 0.95 \\
7010 & 0.92 & 0.79 & 0.94 & 0.93 & 0.98 \\
7011 & 0.98 & 0.96 & 0.94 & 0.93 & 0.90 \\
7012 & 0.95 & 0.96 & 0.92 & 0.91 & 0.98 \\
7013 & 0.87 & 0.79 & 0.93 & 0.98 & 0.97 \\
7014 & 0.93 & 1 & 0.94 & 0.93 & 0.95 \\
7015 & 0.94 & 0.83 & 0.93 & 1 & 0.95 \\
7016 & 0.89 & 0.79 & 0.94 & 0.95 & 0.98 \\
\hline M & 0.92 & 0.86 & 0.93 & 0.93 & 0.95 \\
SD & 0.05 & 0.10 & 0.04 & 0.06 & 0.03 \\
\hline
\end{tabular}

Notes: All measures come the verb and action processing battery (Fiez \& Tranel, 1997).

\subsection{Analyses}

Data were analyzed using Bayesian multilevel logistic regression models, which were created in the Stan computational framework (Carpenter et al., 2017; http://mc-stan.org/) and accessed with the brms package (Bürkner, 2017). The dependent variable in these models was item-level action naming accuracy expressed as a dichotomous variable. Standardized composite 
scores for conceptual action-processing performance (Picture Comparison, Picture Attribute) and lexical action-processing performance (Word Comparison, Word Attribute) were entered as fixed-effect predictors. These composite scores were developed as follows: Individual proportion correct scores for the Picture Comparison, Picture Attribute, Word Comparison, and Word Attribute tasks underwent empirical logit transformations, and these empirical logit scores were z-score transformed and assessed in terms of the assumptions of normality, homoscedasticity, linearity, and the presence of outliers. The z-scores were then averaged for Picture Comparison and Picture Attribute to create the conceptual action-processing composite score and for Word Comparison and Word Attribute to create the lexical action-processing composite score. This model structure allows examination of the effects of conceptual versus lexical action-processing skills on verb retrieval (action naming) ability. Grouping performance on conceptual versus lexical tasks is supported both by the design of the standardized battery (Fiez \& Tranel, 1997) and by a factor analysis conducted in a large sample of neurologically-impaired adults, which indicated that the conceptual (picture-based), lexical (verb-based), and action naming tasks each loaded on separate factors (Kemmerer et al., 2001). Furthermore, the current sample of participants with aphasia demonstrated correlations between the conceptual action-processing tasks (Picture Comparison and Picture Attribute: $r=0.78, \mathrm{p}<0.001$ ) and between the lexical action-processing tasks (Word Comparison and Word Attribute: $r=0.78, \mathrm{p}<0.001$; see Table 5 for full task correlation matrix).

Table 5. Correlation matrix for task performance and severity for participants with aphasia

\begin{tabular}{cccccc}
\hline Action & Picture & Picture & Word & Word \\
Naming & Comparison & Attribute & Comparison & $\begin{array}{c}\text { CAT } \\
\text { Attribute } \\
\text { Modality } \\
\text { Mean }\end{array}$ \\
\hline
\end{tabular}


Random slopes were included for conceptual and lexical z-scores within subjects and aphasia severity within items. Models including more complex random slopes failed to converge.

For both models, each parameter was given dispersed starting values and a vague prior using the default options in brms, thus allowing the Bayesian estimation process to explore the full parameter space and provide conservative estimates of posterior distributions (McElreath, 2018). For each model, four Hamiltonian Bernoulli family Markov chain Monte Carlo (MCMC) chains were run for 20,000 samples, with half of the iterations discarded as warm-up and 10,000 iterations monitored for convergence and parameter estimation. MCMC convergence was assessed graphically by inspection of the autocorrelation and trace plots (Appendix A) and statistically using the Gelman-Rubin potential scale reduction statistic ( $\hat{\mathrm{R}})$ and the number of effective samples (ESS; Tables 6 and 7). The $\hat{R}$ statistic is a ratio of the variance within each chain to the variance pooled across chains. $\hat{R}$ values close to 1 indicate satisfactory convergence of the chains to a stable distribution (Gelman et al., 2013). ESS factors out the autocorrelation in the observed MCMC chains and estimates the number of independent samples that would achieve the same degree of precision for the parameter estimates (Carpenter et al., 2017). Large ESS values indicate satisfactory convergence. The posterior distributions are summarized by the estimated parameters and $95 \%$ highest density credible intervals (HDI). The HDI is comparable to the frequentist confidence interval and is determined as the narrowest interval containing the assigned proportion of the posterior distribution's probability mass within which all values have a higher probability density than any values outside the interval (see Fergadiotis et al., 2019 for further explanation). 


\section{Results}

\subsection{Model 1: Effect of group on action naming performance}

To illustrate the magnitude of group differences in performance, Figure 1 shows untransformed group performance (percent accuracy) on each set of tasks: action naming, lexical tasks, and conceptual tasks. This data is also reported at the participant level in Tables 3-4.

Figure 1. Group-level performance across tasks.
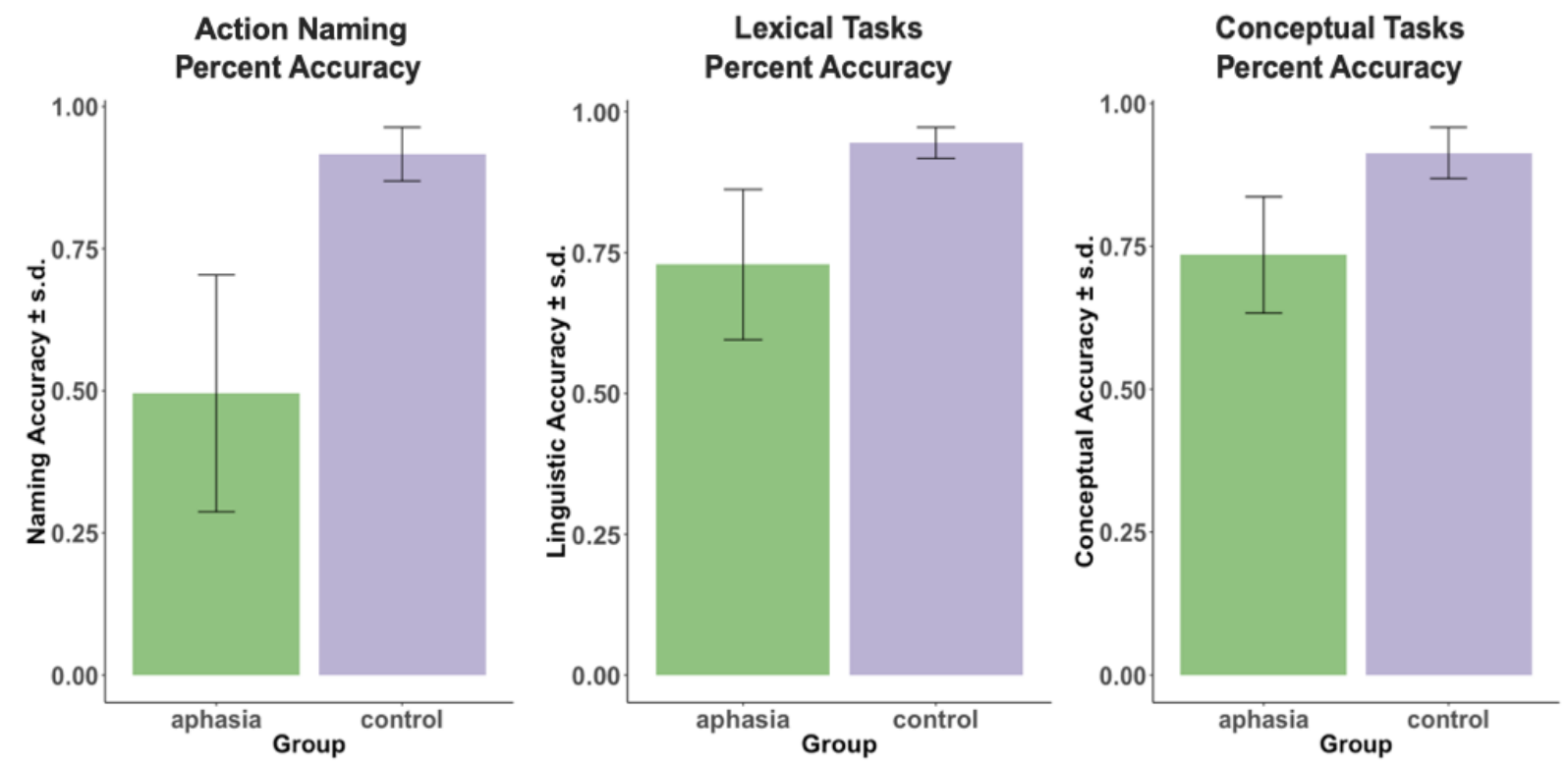

Notes: All group differences were statistically significant (action naming: $\mathrm{t}=7.31, \mathrm{p}<0.001$; lexical tasks: $\mathrm{t}=6.12$, $\mathrm{p}<0.001$, and conceptual tasks: $\mathrm{t}=6.01, \mathrm{p}<0.001)$.

The trace plots for all parameters demonstrated rapid convergence and were stationary relative to the parameter means. There were no divergent transitions. The autocorrelation plots corroborated this assessment and showed minimal autocorrelation. These plots are provided in Appendix A1. The $\hat{R}$ statistic and number of effective samples for each parameter indicated satisfactory convergence and MCMC mixing. These statistics are reported in Table 6. Table 6 
also provides the point estimates, estimated error (EE), and 95\% highest density credible intervals for each parameter. A graphical posterior predictive check of the extent to which the observed data could plausibly have been generated by the estimated model is shown in Figure 2. Histograms of the posterior distributions for the estimates discussed below are provided in Figure 3.

As expected, group (aphasia versus control) reliably predicted trial-level action naming accuracy $(\beta=3.26, \mathrm{EE}=0.38,95 \% \mathrm{HDI}=[2.54,4.07]$; Figure $3 \mathrm{~A})$, with participants with aphasia $(\mathrm{M}=0.495, \mathrm{SD}=0.208)$ performing less well than controls $(\mathrm{M}=0.916, \mathrm{SD}=0.047)$. Furthermore, the effect of group status was influenced by both conceptual and lexical actionprocessing ability, such that aphasia amplified the effect of conceptual $(\beta=-0.54, \mathrm{EE}=0.58$, $95 \% \mathrm{HDI}=[-1.77,0.55])$ and lexical ability $(\beta=-0.30, \mathrm{EE}=0.53,95 \% \mathrm{HDI}=[-1.32,0.76])$ on action naming. Despite these trends, the credible intervals for these effects suggested that they were not reliably different from zero (Figures 3B-C). However, conceptual action-processing ability alone reliably predicted action naming $(\beta=0.82, \mathrm{EE}=0.39,95 \%$ HDI $=[0.09,1.62]$; Figure 3D). In addition, conceptual and lexical action-processing abilities interacted, such that higher conceptual ability reduced the effect of lexical impairments on action naming, and vice versa $(\beta=-0.26, \mathrm{EE}=0.44,95 \% \mathrm{HDI}=[-1.13,0.60])$. Once again, the credible interval indicated that this interaction effect was not reliably different from zero (Figure 3E). The full set of results is reported in Table 6.

Table 6. Model 1 population-level effects for participants with aphasia and age-matched control participants

\begin{tabular}{cccccccc}
\hline & \multirow{2}{*}{ Estimate } & Est. Error & $\begin{array}{c}\text { Lower } \\
95 \% \\
\text { HDI }\end{array}$ & $\begin{array}{c}\text { Upper } \\
95 \% \\
\text { HDI }\end{array}$ & $\hat{\mathrm{R}}$ & $\begin{array}{c}\text { Bulk } \\
\text { ESS }\end{array}$ & $\begin{array}{c}\text { Tail } \\
\text { ESS }\end{array}$ \\
\hline (Intercept) & 0.05 & 0.28 & -0.49 & 0.59 & 1 & 4048 & 5900
\end{tabular}




\begin{tabular}{clllllll} 
Group & 3.26 & 0.38 & 2.54 & 4.07 & 1 & 6655 & 6545 \\
Conceptual action-processing & 0.82 & 0.39 & 0.09 & 1.62 & 1 & 4479 & 5873 \\
Lexical action-processing & 0.31 & 0.38 & -0.45 & 1.03 & 1 & 4021 & 4686 \\
Group : Conceptual & -0.54 & 0.58 & -1.77 & 0.55 & 1 & 4944 & 5132 \\
Group : Lexical & -0.3 & 0.53 & -1.32 & 0.76 & 1 & 4159 & 4539 \\
Conceptual : Lexical & -0.26 & 0.44 & -1.13 & 0.60 & 1 & 3284 & 4700 \\
Group : Conceptual : Lexical & -0.11 & 0.65 & -1.47 & 1.12 & 1 & 3159 & 4559 \\
\hline
\end{tabular}

Notes: Composite scores for conceptual action-processing and lexical action-processing were calculated by an empirical-logit and $z$-score transformation per participant. HDI=Highest density interval. $\hat{\mathrm{R}}=$ The potential scale reduction factor on split chains (at convergence, $\hat{R}=1$ ). ESS=Effective sample size.

Figure 2. Posterior predictive check for Model 1

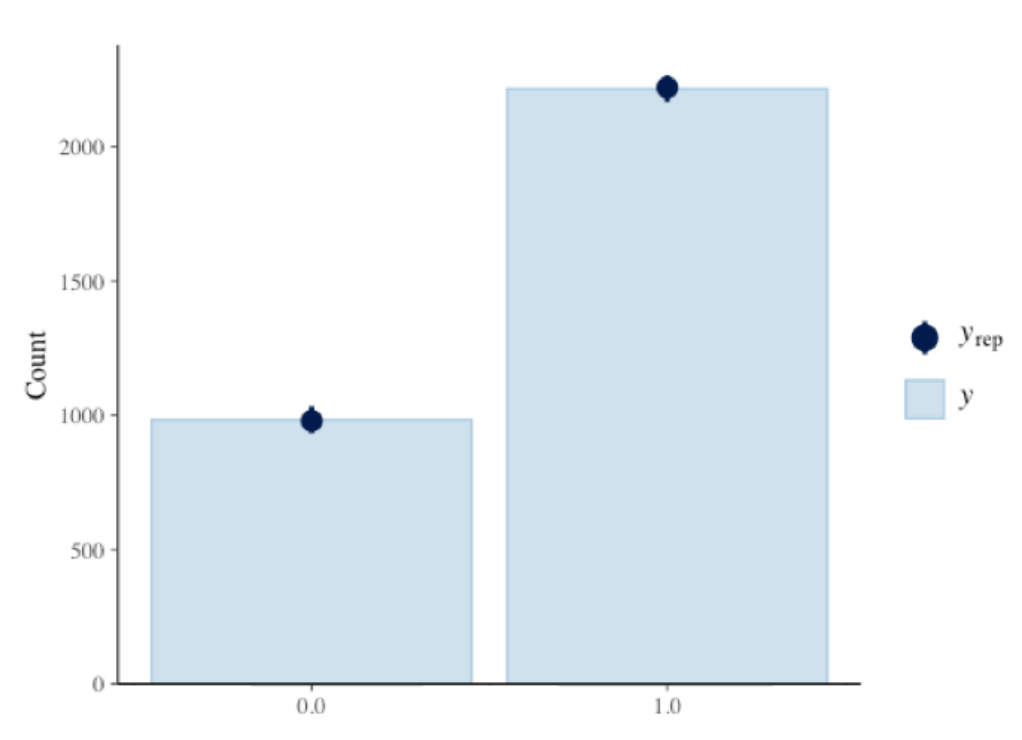

Figure 3. Posterior distributions and $95 \%$ highest density intervals (HDIs) of (A) the fixed effect of group, (B) the interaction effect of group and conceptual action-processing, (C) the interaction effect of group and lexical action-processing, (D) the fixed effect of conceptual action-processing, and (E) the interaction effect of conceptual and lexical action-processing (results from Model 1, participants with aphasia and healthy controls).

Notes: Dashed lines mark the 95\% highest density intervals (HDIs) for the posterior distribution. 


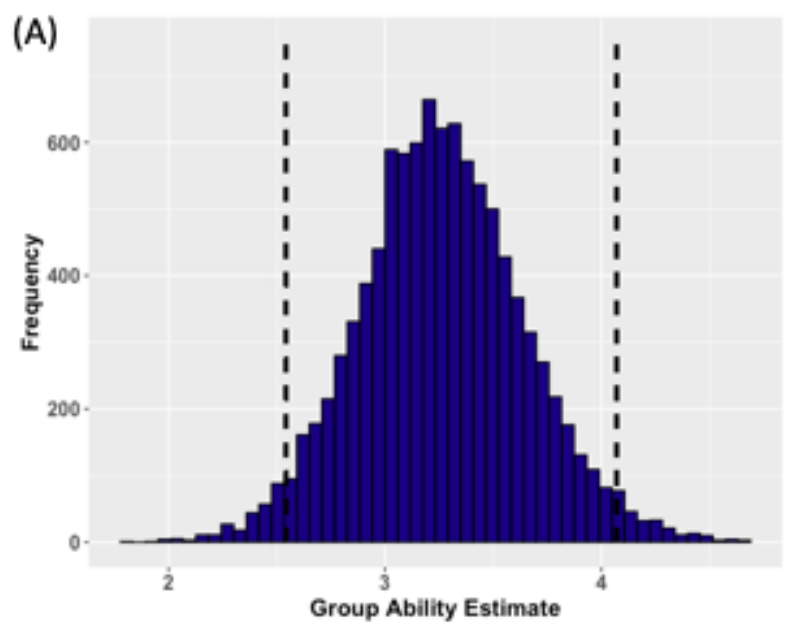

(B) 8

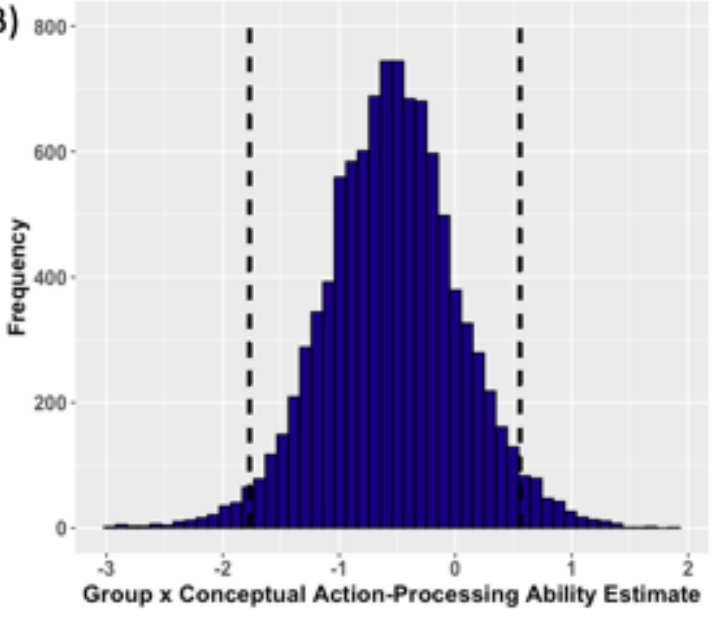

(D)

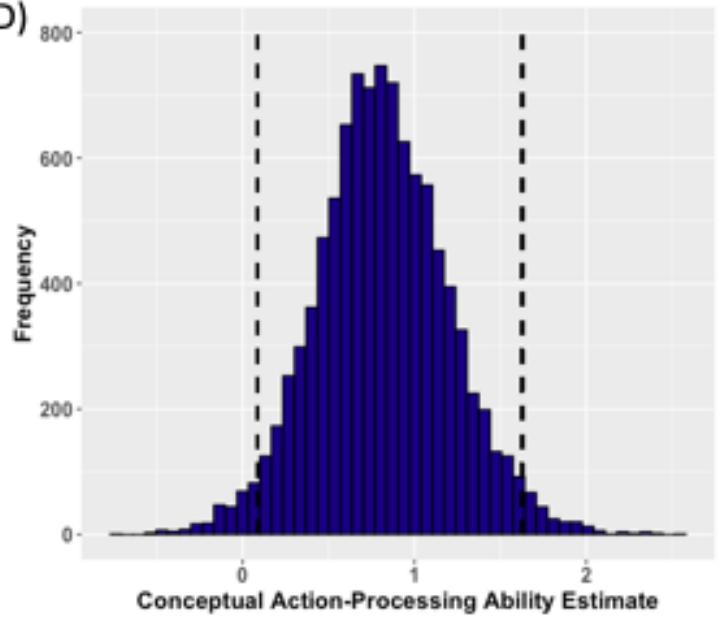

(C) $1000-$

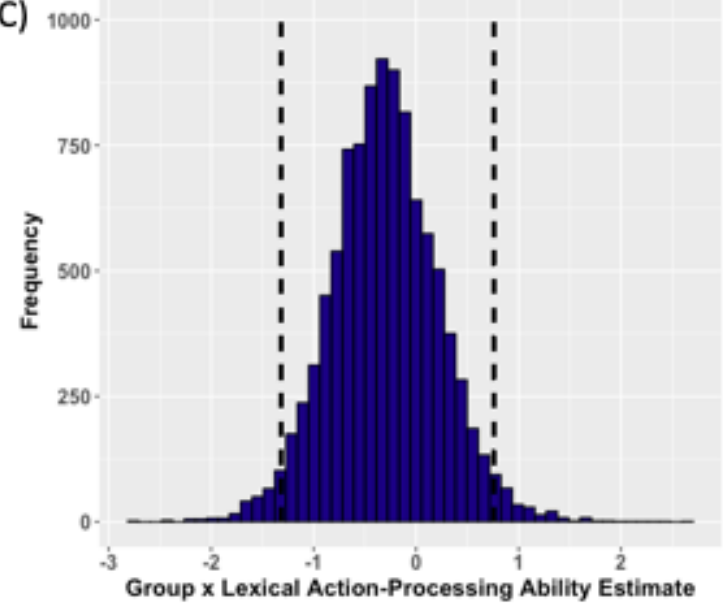

(E)

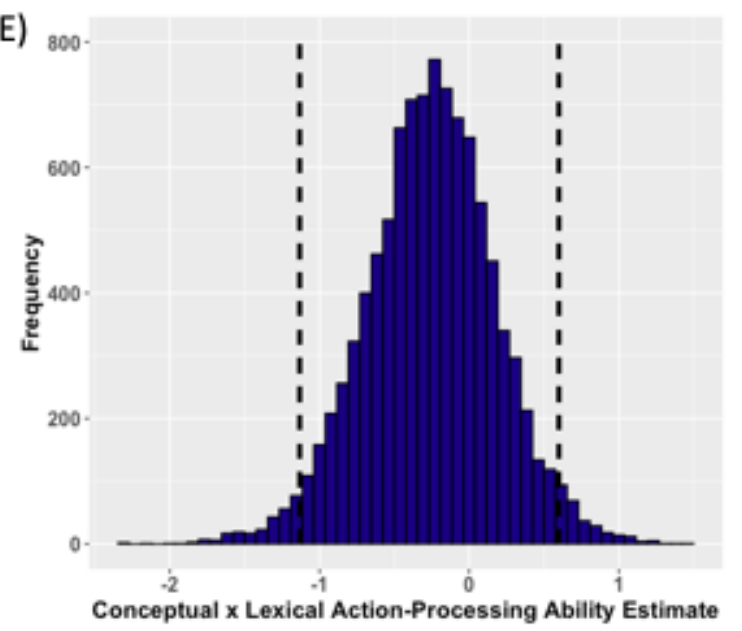




\subsection{Model 2: Conceptual and lexical action-processing associations with verb-retrieval impairments in adults with aphasia}

The trace plots for all parameters demonstrated rapid convergence and were stationary relative to the parameter means. There were no divergent transitions. The autocorrelation plots corroborated this assessment and showed minimal autocorrelation. These plots are provided in Appendix A2. The $\hat{R}$ statistic and number of effective samples for each parameter indicated satisfactory convergence and MCMC mixing. These statistics are reported in Table 7. Table 7 also provides the point estimates and $95 \%$ credible intervals for each parameter. The posterior predictive check is shown in Figure 4. Histograms of the posterior distributions for the estimates discussed below are provided in Figure 5.

Model 2 results indicate that the degree of aphasia severity (CAT) further interacted with both conceptual and lexical action-processing ability, such that milder aphasia amplified the effect of both conceptual $(\beta=1.05, \mathrm{EE}=0.82,95 \% \mathrm{HDI}=[-0.52,2.76]$; Figure $5 \mathrm{~A})$ and lexical ability $(\beta=0.42, \mathrm{EE}=0.52,95 \% \mathrm{HDI}=[-0.69,1.49]$; Figure $5 \mathrm{~B})$ on action naming. Although the $95 \%$ credible intervals for these effects overlapped with zero, 92 percent of the posterior distribution of the interaction effect between severity and conceptual processing exceeded zero, and 83 percent of the posterior distribution of the severity and lexical processing interaction exceeded zero. Parallel to results from Model 1, conceptual action-processing ability alone robustly predicted action naming in participants with aphasia $(\beta=0.93, \mathrm{EE}=0.52,95 \% \mathrm{HDI}=[-$ 0.07, 2.00]; Figure 5C) but lexical action-processing ability did not $(\beta=-0.02, \mathrm{EE}=0.49,95 \%$ HDI $=[-1.00,0.99])$. Furthermore, conceptual and lexical action-processing abilities also interacted to predict naming, such that higher conceptual ability reduced the effect of lexical impairments on action naming, and vice versa $(\beta=-1.15, \mathrm{EE}=0.68,95 \% \mathrm{HDI}=[-2.53,0.15]$; 
Figures 5D). Despite the small overlap of the credible interval with zero, this interaction effect was robust, with a 99.98 percent posterior probability of being less than 0 . The full set of results is reported in Table 7.

Table 7. Model 2 population-level effects for participants with aphasia

\begin{tabular}{cccccccc}
\hline & Estimate & Est. Error & $\begin{array}{c}\text { Lower } \\
95 \% \\
\text { HDI }\end{array}$ & $\begin{array}{c}\text { Upper } \\
\text { 95\% } \\
\text { HDI }\end{array}$ & $\hat{\text { R }}$ & $\begin{array}{c}\text { Bulk } \\
\text { ESS }\end{array}$ & $\begin{array}{c}\text { Tail } \\
\text { ESS }\end{array}$ \\
\hline (Intercept) & -0.02 & 0.32 & -0.66 & 0.62 & 1 & 1431 & 1895 \\
Aphasia severity & 0.14 & 0.35 & -0.52 & 0.85 & 1 & 1128 & 1225 \\
Conceptual action-processing & 0.93 & 0.52 & -0.07 & 2.00 & 1 & 1455 & 1601 \\
Lexical action-processing & -0.02 & 0.49 & -1.00 & 0.99 & 1 & 1511 & 1146 \\
Severity : Conceptual & 1.05 & 0.82 & -0.52 & 2.76 & 1 & 1039 & 942 \\
Severity : Lexical & 0.42 & 0.52 & -0.60 & 1.49 & 1 & 1292 & 1064 \\
Conceptual : Lexical & -1.15 & 0.68 & -2.53 & 0.15 & 1 & 884 & 1156 \\
Severity : Conceptual : Lexical & -0.03 & 0.62 & -1.25 & 1.27 & 1 & 1671 & 1784 \\
\hline
\end{tabular}

Notes: Aphasia severity was z-score transformed CAT modality mean score. Composite scores for conceptual action-processing and lexical action-processing were calculated by an empirical-logit and z-score transformation per participant. HDI=Highest density interval. $\hat{\mathrm{R}}=$ The potential scale reduction factor on split chains (at convergence, $\hat{\mathrm{R}}$ $=1)$. $\mathrm{ESS}=$ Effective sample size.

Figure 4. Posterior predictive check for Model 2

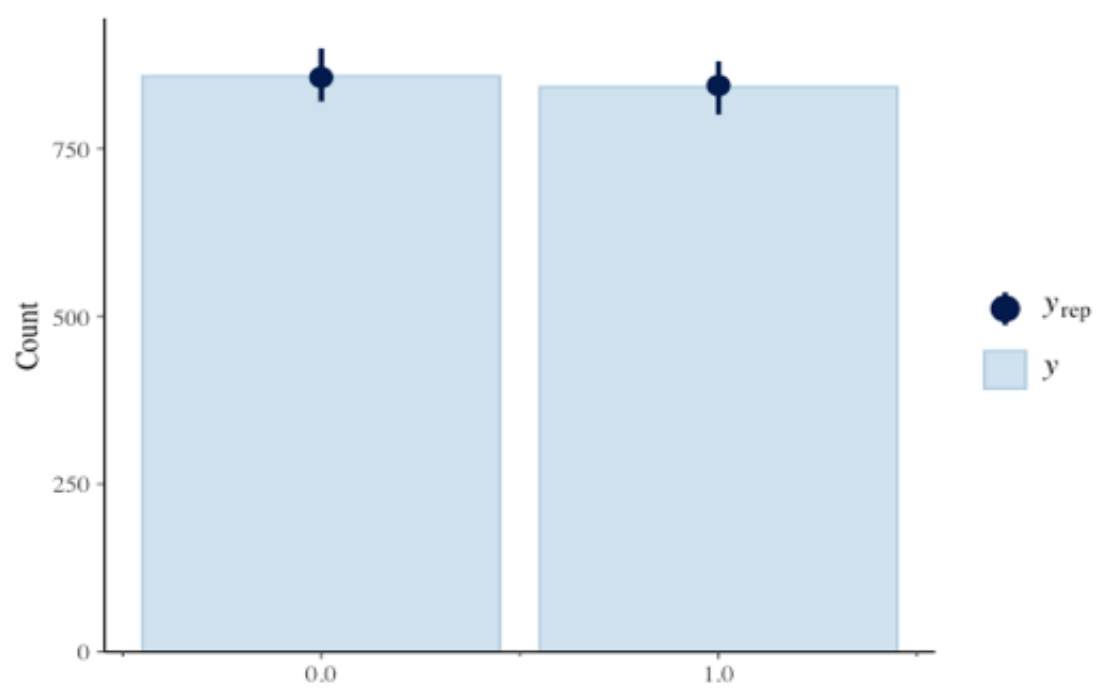


Figure 5. Posterior distributions and $95 \%$ highest density intervals (HDIs) of (A) the interaction effect of aphasia severity and conceptual action-processing, (B) the interaction effect of aphasia severity and lexical action-processing, (C) the fixed effect of conceptual action-processing, and (D) the interaction effect of conceptual and lexical action-processing (results from Model 2, participants with aphasia).

Notes: Dashed lines mark the 95\% highest density intervals (HDIs) for the posterior distribution.
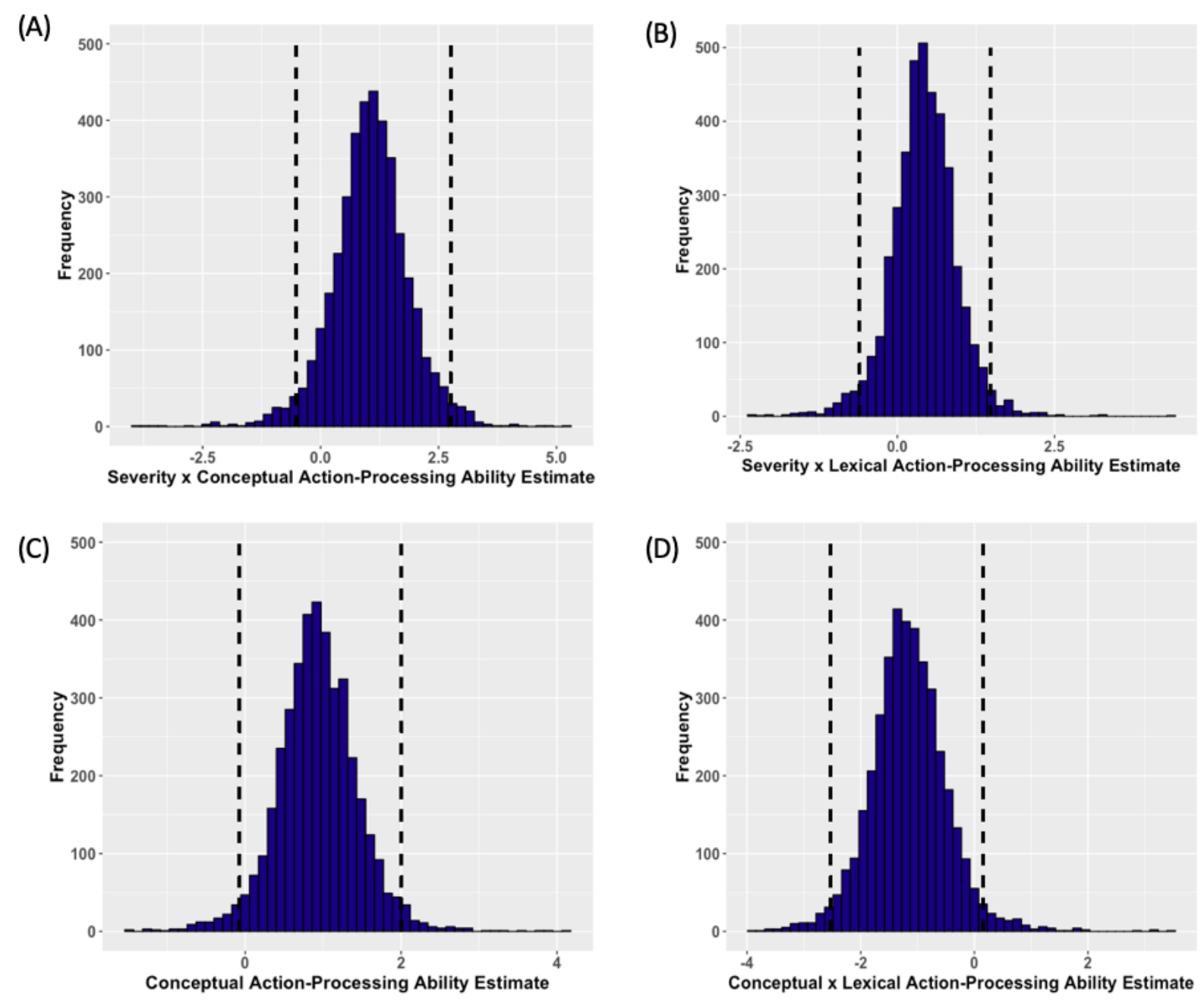

\section{Discussion}

The purpose of this study was to examine how deficits in lexical and conceptual actionprocessing each contribute to verb-retrieval impairments in aphasia. Lexical and conceptual action-processing deficits often co-occur in neurologically-impaired individuals (Kemmerer et 
al., 2001, 2012), and there are separate bodies of evidence that lexical properties and conceptual representations may help to characterize verb-retrieval deficits (lexical: Barde et al., 2006; Kim \& Thompson, 2004; Malyutina, Richardson, et al., 2016; conceptual: Bak, 2013; Bak \& Chandran, 2012). However, there is no evidence to date regarding the interactions or potential tradeoffs between lexical and conceptual deficits, and how they jointly impact language functions like naming. Furthermore, there is conflicting evidence regarding whether or when lexical and conceptual action-processing deficits may dissociate following stroke (Dresang et al., 2019; Kemmerer et al., 2012; Saygin et al., 2004). Thus, the contributions of lexical and conceptual action-processing deficits to verb-retrieval impairments in aphasia remain unclear. To our knowledge, this is the first study to directly examine how lexical and conceptual processing abilities predict action naming in aphasia.

In this study, 17 individuals with chronic aphasia due to unilateral left hemisphere stroke and 15 age-matched neurotypical controls completed a standardized action knowledge battery (Fiez \& Tranel, 1997) to assess participants' lexical and conceptual action-processing abilities. Each participant completed (1) a verb retrieval task (action naming), (2) two conceptual, picturebased tasks (picture attribute and picture comparison judgments), and (3) two linguistic, verbbased tasks (word attribute and word comparison judgments).

Participants with aphasia performed reliably less well than controls in all three sets of tasks: lexical and conceptual action processing, as well as action naming. These findings replicate previous findings that action naming (verb retrieval) is commonly impaired in aphasia, with approximately $70 \%$ of individuals with aphasia experiencing verb-retrieval deficits (Mätzig et al., 2009). They are also consistent with previous findings indicating that both conceptual and lexical action processing may be impaired following stroke (Kemmerer et al., 2012) and in 
aphasia more specifically (Saygin et al., 2004). Notably, both conceptual and lexical abilities predicted action-naming performance, and the presence of aphasia amplified the effects of both individual factors on naming performance. Furthermore, the effects of both conceptual and lexical abilities on action naming were greater for individuals with more mild aphasia, as measured by the CAT Modality Mean T Score (Swinburn et al., 2004). These findings provide deeper insight into the relationship reported by Saygin and colleagues (2004), who found that individuals with mild and fluent aphasia showed correlated performance on conceptual and linguistic tasks, whereas relatively severe and nonfluent individuals showed disproportionately more impaired linguistic performance. The current study demonstrates that regardless of conceptual-linguistic correlations, individuals with more mild aphasia experience a more robust effect of both conceptual and lexical action-processing deficits on naming. These findings are novel, and they provide evidence that both lexical and conceptual processing contribute to verbretrieval impairments in aphasia.

Notably, the effect of conceptual processing appeared more robust than the effect of lexical processing on action naming. Critically, lexical processing on its own was not a reliable predictor of verb retrieval in people with aphasia. Rather, there was a main effect of conceptual action-processing as well as an interaction between lexical and conceptual processing that robustly predicted verb-retrieval impairments. This pattern of findings is consistent with the second hypothesis described in the introduction, that both lexical and conceptual deficits are key predictors of verb-retrieval impairments in aphasia.

These findings offer less support for the first hypothesis considered in the introduction, which predicted that lexical (and not conceptual) deficits would be the key drivers of verbretrieval impairments in aphasia. Verb-retrieval impairments are traditionally considered to be 
disruptions in the ability to retrieve precise lexical representations (Barde et al., 2006; Bastiaanse \& Jonkers, 1998; Berndt et al., 1997; Breedin et al., 1998; Cho-Reyes \& Thompson, 2012; Gordon \& Dell, 2003). The current findings challenge this view by indicating that breakdowns in conceptual processing also contribute to aphasia's hallmark naming impairments, perhaps even more strongly than breakdowns in lexical processing These results echo and extend previous findings that people with aphasia have both linguistic and conceptual-semantic deficits (Antonucci \& Reilly, 2008; Howard \& Gatehouse, 2006; Jefferies \& Lambon Ralph, 2006; Saygin et al., 2004; progressive aphasia: Lambon Ralph \& Howard, 2000), and that these impairments extend to conceptual action-processing (Dresang et al., 2019). Dresang, Dickey, and Warren (2019) hypothesized that these co-impairments might results from breakdowns in the dynamics between conceptual-semantic and language systems, specifically where conceptualsemantics interfaces with the functional processing stage of language which includes lexical selection (Bock \& Levelt, 1994). The current finding of robust interactions between lexical and conceptual abilities is in line with this hypothesis, and it more specifically predicts that individuals with relatively intact conceptual action-processing may perform well on verb retrieval despite language impairments at the lexical (functional processing) stage.

While previous work has focused on characterizing conceptual and lexical actionprocessing deficits, this study is the first to tease apart the independent contributions and potential interactions of these deficits on verb-retrieval impairments. The current results extend findings that action naming and conceptual and lexical action-processing were associated with ('loaded on') separate factors (Kemmerer et al., 2001). Our study further elucidates the interaction between conceptual and linguistic deficits, which advances previous work showing associations as well as dissociations between conceptual and linguistic deficits in aphasia and 
neurological injury more broadly (Kemmerer et al., 2012; Saygin et al., 2004). The current findings underline the interactivity between the conceptual and lexical processing systems, with strong conceptual skills attenuating and outweighing the effects of lexical impairments on action naming, and vice versa. These findings highlight the importance of interactions between lexical and conceptual systems to characterizing verb-retrieval performance in aphasia and other neurological conditions (Bak, 2013; Pulvermüller, 2018; Vigliocco et al., 2011).

The precise mechanisms underlying this interaction remain unclear, but the robust interactivity between conceptual and lexical ability suggests potential trade-offs between these systems. This is consistent with the information-theoretic principle of rational adaption, which predicts that people rely on different information sources as needed to optimize behavior for the specific situation at hand 7/5/2021 4:45:00 PM. In particular, rational adaptation would predict that when the lexical system is more impaired and less reliable, individuals with aphasia should rely more on conceptual-semantic systems to support language tasks like verb retrieval. This is consistent with the finding that for individuals with low lexical ability, increases in conceptual performance were associated with greater increases in naming, compared to people with more mild lexical deficits. However, the aphasia severity findings appear less consistent with the principle of rational adaptation: rational adaptation would predict that individuals with more severe aphasia should show a stronger effect of conceptual processing on verb retrieval. It is likely that the current study was underpowered to detect a robust three-way-interaction between severity, conceptual, and lexical processing due to large variability in aphasia and a modest sample size. It is also possible that overall severity measures are too broad or insufficiently sensitive/specific to detect this relationship. In addition, individuals with aphasia may need a certain level of word-retrieval ability to show independent effects for lexical and conceptual 
processing ability on verb retrieval. Although the current findings indicate that conceptual and linguistic systems interact in a way that may be characterized by rational adaptation, additional research must assess under what task- and patient-specific circumstances a tradeoff between these systems is likely to occur (Dresang, Warren, et al., 2021).

Notably, these findings underscore that stronger conceptual action-processing is associated with less impaired verb retrieval, regardless of lexical action-processing ability. This has a critical message for rehabilitation: treatments targeting conceptual-semantic performance should be able to ameliorate action-naming deficits in adults with stroke aphasia. This is consistent with the hypothesized mechanism of action underlying efficacious speech-language treatments like Semantic Feature Analysis (SFA; Boyle, 2010), SFA for Actions (Wambaugh et al., 2014), and Verb Network Strengthening Treatment (VNeST; Edmonds, 2016). These interventions aim to promote improved lexical retrieval abilities beyond items that are explicitly trained, so that participants may be able to improve lexical retrieval both for related but untreated items and across a hierarchy of linguistic contexts, including sentences and discourses. VNeST is a particularly relevant intervention because it depends on the semantic (and syntactic) centrality of verbs in language (Edmonds, 2016). The hypothesis is that systematic activation of conceptually related thematic roles promotes increased activation of semantic "verb networks" (Edmonds, 2016), based on evidence for bidirectional priming and facilitation effects between verbs and their thematic roles (e.g., Ferretti et al., 2001; McRae et al., 2005). Although there is individual variability in response to treatment, VNeST has shown promise in exhibiting robust improvements in noun and verb naming, as well as generalization to lexical retrieval in sentences and discourses (Edmonds, 2016). Although individuals with mild and moderate-to-severe fluent and nonfluent aphasia have shown improvements under these interventions, additional research 
like the current study is needed to divulge person-specific predictors and neurocognitive mechanisms underlying these treatments.

Finally, future research must examine the effects of person-specific properties on the benefit of conceptual action-processing, particularly in language rehabilitation. This study offers preliminary evidence that individuals who have milder aphasia may exhibit amplified effects of conceptual processing on naming ability compared to participants with greater severity. This suggests that people with milder language impairments might respond particularly well to treatments that target lexical retrieval via strengthening conceptual-semantic networks (e.g., VNeST, Edmonds, 2016). More detailed individual-level assessments may reveal patient profiles that are most likely to respond to conceptual-semantic interventions for language rehabilitation. It will be critical to explore the sensitivity and predictive value of assessments in greater detail, particularly given evidence from both patient case studies (Lambon Ralph \& Howard, 2000) and computational models (Lambon Ralph et al., 2001) suggesting that semantic impairments can contribute to word-retrieval deficits even when these impairments may not be detected by conventional comprehension tests.

\section{Conclusion}

This study found evidence that lexical and conceptual action-processing interact to support verb retrieval. Impairments to both lexical and conceptual action-processing are prevalent in adults with stroke aphasia, and conceptual processing interacts to offset the impact of lexical deficits on verb-retrieval performance. Theories of language processing and aphasic language impairments must be able to account for these findings demonstrating conceptualsemantic impairments in aphasia and indicating high interactivity between lexical and conceptual 
processing systems. Critically, rehabilitation approaches may be able to leverage these interactions between lexical and conceptual processing systems to facilitate language rehabilitation, although further work is needed to characterize the mechanisms by which these systems interact in both healthy and disordered language users.

Conflict of Interest: The authors declare that the research was conducted in the absence of any commercial or financial relationships that could be construed as a potential conflict of interest.

Author Contributions: H.D., W.H., T.W., and M.W.D. conceived of the presented idea. H.D. carried out the experiment, supervised by M.W.D. H.D. performed the computations and W.H. verified the analytical methods. H.D. wrote the manuscript with support from T.W. and M.W.D. All authors discussed the results and contributed to the final manuscript.

Funding: This research was supported through funding received from the National Institutes of Health (NIH) National Institute on Deafness and Other Communication Disorders (NIDCD) F31DC017896; the William Orr Dingwall Foundation's Dissertation Fellowship in the Cognitive, Clinical, and Neural Foundations of Language; the Council of Academic Programs in Communication Sciences and Disorders (CAPCSD) Ph.D. Scholarship; the Audrey Holland Endowed Student Resource Fund; and the University of Pittsburgh's School of Health and Rehabilitation Sciences (SHRS) Ph.D. Student Award for dissertation research.

Acknowledgments: The authors thank the Language and Brain Lab and High-Definition Fiber Tractography Lab for experimental support. 


\section{References}

Antonucci, S. M., \& Reilly, J. (2008). Semantic memory and language processing: A primer. Seminars in Speech and Language, 29(1), 5-17. https://doi.org/10.1055/s-2008-1061621

Bak, T. H. (2013). The neuroscience of action semantics in neurodegenerative brain diseases: Current Opinion in Neurology, 26(6), 671-677. https://doi.org/10.1097/WCO.0000000000000039

Bak, T. H., \& Chandran, S. (2012). What wires together dies together: Verbs, actions and neurodegeneration in motor neuron disease. Cortex, 48(7), 936-944. https://doi.org/10.1016/j.cortex.2011.07.008

Bak, T. H., \& Hodges, J. R. (2003). Kissing and dancing-A test to distinguish the lexical and conceptual contributions to noun/verb and action/object dissociation. Preliminary results in patients with frontotemporal dementia. Journal of Neurolinguistics, 16(2), 169-181.

Barde, L. H., Schwartz, M. F., \& Boronat, C. B. (2006). Semantic weight and verb retrieval in aphasia. Brain and Language, 97(3), 266-278.

Bastiaanse, R., \& Jonkers, R. (1998). Verb retrieval in action naming and spontaneous speech in agrammatic and anomic aphasia. Aphasiology, 12(11), 951-969.

Berndt, R. S., Mitchum, C. C., \& Wayland, S. (1997). Patterns of sentence comprehension in aphasia: A consideration of three hypotheses. Brain and Language, 60(2), 197-221.

Bock, K., \& Levelt, W. (1994). Language production: Grammatical encoding. Handbook of psycholinguistics, ed. By Morton Ann Gernsbacher, 945-84.

Boulenger, V., Hauk, O., \& Pulvermüller, F. (2009). Grasping ideas with the motor system: Semantic somatotopy in idiom comprehension. Cerebral Cortex, 19(8), 1905-1914.

Boyle, M. (2010). Semantic feature analysis treatment for aphasic word retrieval impairments: What's in a name? Topics in Stroke Rehabilitation, 17(6), 411-422.

Breedin, S. D., Saffran, E. M., \& Schwartz, M. F. (1998). Semantic factors in verb retrieval: An effect of complexity. Brain and Language, 63(1), 1-31. https://doi.org/10.1006/brln.1997.1923

Bürkner, P. (2017). brms: An R Package for Bayesian Multilevel Models Using Stan. Journal of Statistical Software, 80(1), 1-28. http://dx.doi.org/10.18637/jss.v080.i01

Caramazza, A., \& Hillis, A. E. (1991). Lexical organization of nouns and verbs in the brain. Nature, 349(6312), 788-790. https://doi.org/10.1038/349788a0

Carpenter, B., Gelman, A., Hoffman, M. D., Lee, D., Goodrich, B., Betancourt, M., Brubaker, M., Guo, J., Li, P., \& Riddell, A. (2017). Stan: A Probabilistic Programming Language. Journal of Statistical Software, 76(1), 1-32. https://doi.org/10.18637/jss.v076.i01

Cho-Reyes, S., \& Thompson, C. K. (2012). Verb and sentence production and comprehension in aphasia: Northwestern Assessment of Verbs and Sentences (NAVS). Aphasiology, 26(10), 1250-1277.

Dresang, H. C., Dickey, M. W., \& Warren, T. C. (2019). Semantic memory for objects, actions, and events: A novel test of event-related conceptual semantic knowledge. Cognitive Neuropsychology, 36(7-8), 313-335. https://doi.org/10.1080/02643294.2019.1656604

Dresang, H. C., Hula, W. D., Yeh, F.-C., Warren, T., \& Dickey, M. W. (2021). White matter neuroanatomical predictors of aphasic verb retrieval. Brain Connectivity, brain.2020.0921. https://doi.org/10.1089/brain.2020.0921 
Dresang, H. C., Warren, T., Hula, W. D., \& Dickey, M. W. (2021). Rational adaptation in using conceptual versus lexical information in adults with aphasia. Frontiers in Psychology, 12. https://doi.org/10.3389/fpsyg.2021.589930

Edmonds, L. A. (2016). A Review of Verb Network Strengthening Treatment: Theory, Methods, Results, and Clinical Implications. Topics in Language Disorders, 36(2), 123-135.

Elman, J. L., \& McRae, K. (2019). A model of event knowledge. Psychological Review, 126(2), 252-291. https://doi.org/10.1037/rev0000133

Fergadiotis, G., Hula, W. D., Swiderski, A. M., Lei, C.-M., \& Kellough, S. (2019). Enhancing the Efficiency of Confrontation Naming Assessment for Aphasia Using Computer Adaptive Testing. Journal of Speech, Language, and Hearing Research: JSLHR, 62(6), 1724-1738. https://doi.org/10.1044/2018_JSLHR-L-18-0344

Ferretti, T. R., McRae, K., \& Hatherell, A. (2001). Integrating verbs, situation schemas, and thematic role concepts. Journal of Memory and Language, 44(4), 516-547.

Fiez, J. A., \& Tranel, D. (1997). Standardized stimuli and procedures for investigating the retrieval of lexical and conceptual knowledge for actions. Memory \& Cognition, 25(4), 543-569. https://doi.org/10.3758/BF03201129

Folstein, M. F., Folstein, S. E., \& McHugh, P. R. (1975). "Mini-mental state": A practical method for grading the cognitive state of patients for the clinician. Journal of Psychiatric Research, 12(3), 189-198.

Gelman, A., Carlin, J., Stern, H., Dunson, D., Vehtari, A., \& Rubin, D. (2013). Bayesian data analysis (3rd ed.). CRC Press.

Gerfo, E. L., Oliveri, M., Torriero, S., Salerno, S., Koch, G., \& Caltagirone, C. (2008). The influence of rTMS over prefrontal and motor areas in a morphological task: Grammatical vs. semantic effects. Neuropsychologia, 46(2), 764-770. https://doi.org/10.1016/j.neuropsychologia.2007.10.012

Gordon, J. K., \& Dell, G. S. (2003). Learning to divide the labor: An account of deficits in light and heavy verb production. Cognitive Science, 27(1), 1-40. https://doi.org/10.1016/S0364-0213(02)00111-8

Hauk, O., Johnsrude, I., \& Pulvermüller, F. (2004). Somatotopic representation of action words in human motor and premotor cortex. Neuron, 41(2), 301-307.

Howard, D., \& Gatehouse, C. (2006). Distinguishing semantic and lexical word retrieval deficits in people with aphasia. Aphasiology, 20(9-11), 921-950. https://doi.org/10.1080/02687030600782679

Hula, W. D., Panesar, S., Gravier, M. L., Yeh, F.-C., Dresang, H. C., Dickey, M. W., \& Fernandez-Miranda, J. C. (2020). Structural white matter connectometry of word production in aphasia: An observational study. Brain, 143(8), 2532-2544. https://doi.org/10.1093/brain/awaa193

Jefferies, E., \& Ralph, M. A. L. (2006). Semantic impairment in stroke aphasia versus semantic dementia: A case-series comparison. Brain, 129(8), 2132-2147.

Kemmerer, D., Rudrauf, D., Manzel, K., \& Tranel, D. (2012). Behavioral patterns and lesion sites associated with impaired processing of lexical and conceptual knowledge of actions. Cortex, 48(7), 826-848. https://doi.org/10.1016/j.cortex.2010.11.001

Kemmerer, D., Tranel, D., \& Barrash, J. (2001). Patterns of dissociation in the processing of verb meanings in brain-damaged subjects. Language and Cognitive Processes, 16(1), 1-34. https://doi.org/10.1080/01690960042000175 
Kim, M., \& Thompson, C. K. (2000). Patterns of comprehension and production of nouns and verbs in agrammatism: Implications for lexical organization. Brain and Language, 74(1), $1-25$.

Kim, M., \& Thompson, C. K. (2004). Verb deficits in Alzheimer's disease and agrammatism: Implications for lexical organization. Brain and Language, 88(1), 1-20.

Lambon Ralph, M. A., McClelland, J. L., Patterson, K., Galton, C. J., \& Hodges, J. R. (2001). No right to speak? The relationship between object naming and semantic impairment: neuropsychological evidence and a computational model. Journal of Cognitive Neuroscience, 13(3), 341-356. https://doi.org/10.1162/08989290151137395

Links, P., Hurkmans, J., \& Bastiaanse, R. (2010). Training verb and sentence production in agrammatic Broca's aphasia. Aphasiology, 24(11), 1303-1325. https://doi.org/10.1080/02687030903437666

Liuzzi, G., Freundlieb, N., Ridder, V., Hoppe, J., Heise, K., Zimerman, M., Dobel, C., EnriquezGeppert, S., Gerloff, C., \& Zwitserlood, P. (2010). The involvement of the left motor cortex in learning of a novel action word lexicon. Current Biology, 20(19), 1745-1751.

Loverso, F., Prescott, T., \& Selinger, M. (1988). Cueing verbs: A treatment strategy for aphasic adults (CVT). Journal of Rehabilitation Research and Development, 25(2), 47-60.

Malyutina, S., Dragoy, O., Ivanova, M., Laurinavichyute, A., Petrushevsky, A., Meindl, T., Pöppel, E., \& Gutyrchik, E. (2016). Fishing is not wrestling: Neural underpinnings of the verb instrumentality effect. Journal of Neurolinguistics, 40, 37-54. https://doi.org/10.1016/j.jneuroling.2016.03.002

Malyutina, S., Richardson, J. D., \& den Ouden, D. B. (2016). Verb Argument Structure in Narrative Speech: Mining AphasiaBank. Seminars in Speech and Language, 37(1), 3447. PubMed. https://doi.org/10.1055/s-0036-1572383

Mätzig, S., Druks, J., Masterson, J., \& Vigliocco, G. (2009). Noun and verb differences in picture naming: Past studies and new evidence. Cortex, 45(6), 738-758.

McElreath, R. (2018). Statistical rethinking: A Bayesian course with examples in $R$ and Stan. Chapman and Hall/CRC.

McRae, K., Hare, M., Elman, J. L., \& Ferretti, T. (2005). A basis for generating expectancies for verbs from nouns. Memory \& Cognition, 33(7), 1174-1184.

McRae, K., \& Matsuki, K. (2009). People use their knowledge of common events to understand language, and do so as quickly as possible. Language and Linguistics Compass, 3(6), 1417-1429.

Pulvermüller, F. (2005). Brain mechanisms linking language and action. Nature Reviews Neuroscience, 6(7), 576-582. https://doi.org/10.1038/nrn1706

Pulvermüller, F. (2018). Neural reuse of action perception circuits for language, concepts and communication. Progress in Neurobiology, 160, 1-44. https://doi.org/10.1016/j.pneurobio.2017.07.001

Pulvermüller, F., Hauk, O., Nikulin, V. V., \& Ilmoniemi, R. J. (2005). Functional links between motor and language systems. The European Journal of Neuroscience, 21(3), 793-797. https://doi.org/10.1111/j.1460-9568.2005.03900.x

Ralph, M. A., \& Howard, D. (2000). Gogi aphasia or semantic dementia? Simulating and assessing poor verbal comprehension in a case of progressive fluent aphasia. Cognitive Neuropsychology, 17(5), 437-465. https://doi.org/10.1080/026432900410784

Raven, J. C. (1965). Guide to using the coloured progressive matrices: Sets $A, A b, B$. William Grieve \& Sons. 
Roberts, A., Nguyen, P., Orange, J. B., Jog, M., Nisbet, K. A., \& McRae, K. (2017). Differential impairments of upper and lower limb movements influence action verb processing in Parkinson disease. Cortex, 97, 49-59. https://doi.org/10.1016/j.cortex.2017.09.022

Rofes, A., Capasso, R., \& Miceli, G. (2015). Verb production tasks in the measurement of communicative abilities in aphasia. Journal of Clinical and Experimental Neuropsychology, 37(5), 483-502. https://doi.org/10.1080/13803395.2015.1025709

Rose, M., \& Sussmilch, G. (2008). The effects of semantic and gesture treatments on verb retrieval and verb use in aphasia. Aphasiology, 22(7-8), 691-706.

Saygin, A. P., Wilson, S. M., Dronkers, N. F., \& Bates, E. (2004). Action comprehension in aphasia: Linguistic and non-linguistic deficits and their lesion correlates. Neuropsychologia, 42(13), 1788-1804. https://doi.org/10.1016/j.neuropsychologia.2004.04.016

Shapiro, L. P., \& Levine, B. A. (1990). Verb processing during sentence comprehension in aphasia. Brain and Language, 38(1), 21-47.

Swinburn, K., Porter, G., \& Howard, D. (2004). CAT: comprehensive aphasia test. Psychology Press.

Thompson, C. K. (2003). Unaccusative verb production in agrammatic aphasia: The argument structure complexity hypothesis. Journal of Neurolinguistics, 16, 151-167.

Thompson, C. K., Lukic, S., King, M. C., Mesulam, M. M., \& Weintraub, S. (2012). Verb and noun deficits in stroke-induced and primary progressive aphasia: The Northwestern Naming Battery. Aphasiology, 26(5), 632-655. https://doi.org/10.1080/02687038.2012.676852

Thompson, C., \& Shapiro, L. (2005). Treating agrammatic aphasia within a linguistic framework: Treatment of Underlying Forms. Aphasiology, 19(10-11), 1021-1036.

Thorne, J., \& Faroqi-Shah, Y. (2016). Verb production in aphasia: Testing the division of labor between syntax and semantics. Seminars in Speech and Language, 37(1), 23-33. https://doi.org/10.1055/s-0036-1571356

Vigliocco, G., Vinson, D. P., Druks, J., Barber, H., \& Cappa, S. F. (2011). Nouns and verbs in the brain: A review of behavioural, electrophysiological, neuropsychological and imaging studies. Neuroscience \& Biobehavioral Reviews, 35(3), 407-426. https://doi.org/10.1016/j.neubiorev.2010.04.007

Wambaugh, J. L., Mauszycki, S., \& Wright, S. (2014). Semantic feature analysis: Application to confrontation naming of actions in aphasia. Aphasiology, 28(1), 1-24. https://doi.org/10.1080/02687038.2013.845739

Yang, Y., Dickey, M. W., Fiez, J., Murphy, B., Mitchell, T., Collinger, J., Tyler-Kabara, E., Boninger, M., \& Wang, W. (2017). Sensorimotor experience and verb-category mapping in human sensory, motor and parietal neurons. Cortex, 92, 304-319.

Zwaan, R. A. (2015). Situation models, mental simulations, and abstract concepts in discourse comprehension. Psychonomic Bulletin \& Review, 1-7. 


\section{Appendix A}

\section{A.1 Trace and density plots for MCMC samples for Model 1}
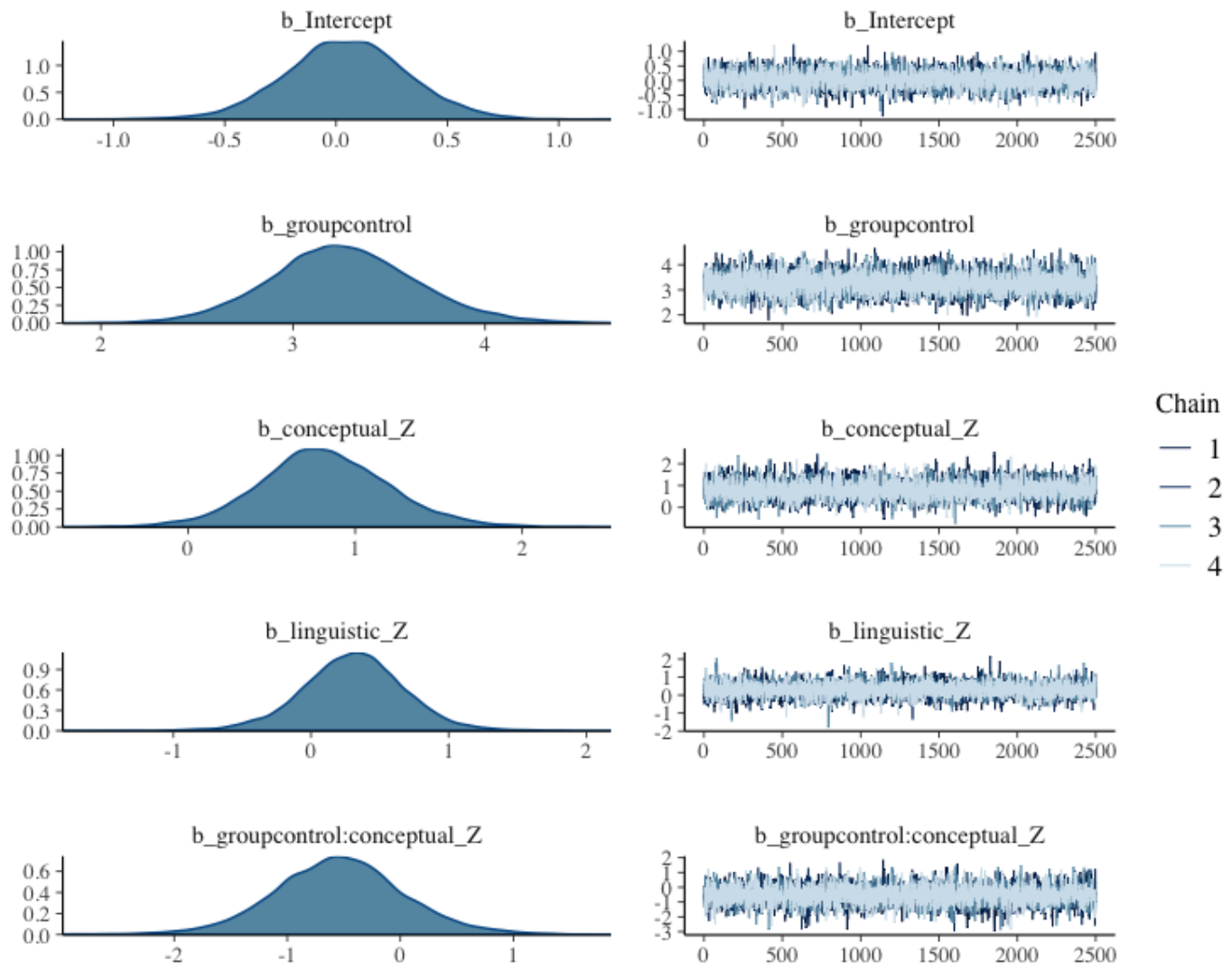

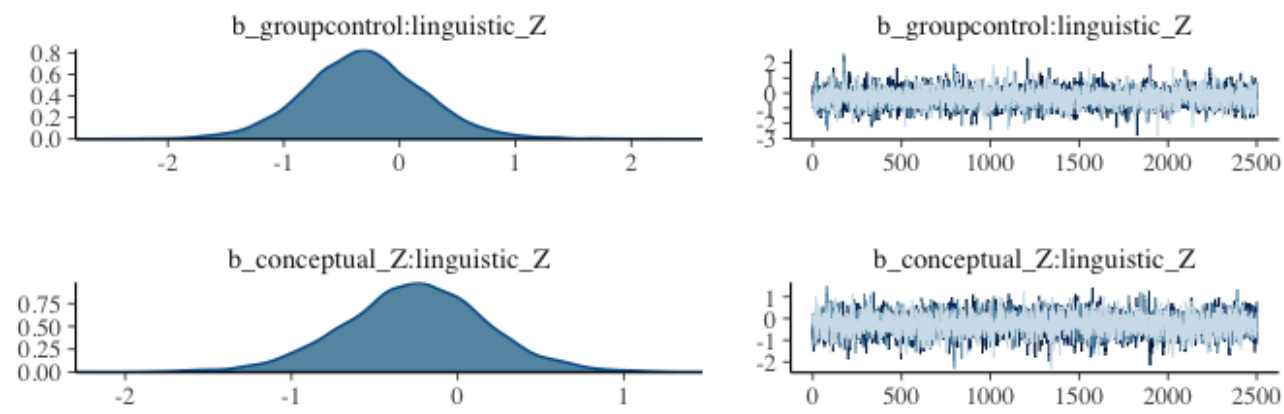

b_conceptual_Z:linguistic_Z

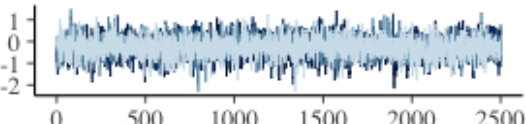

b_groupcontrol:conceptual_Z:linguistic_Z

b_groupcontrol:conceptual_Z:linguistic_Z

Chain

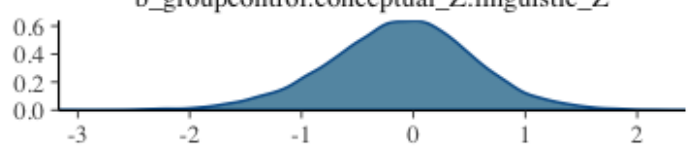

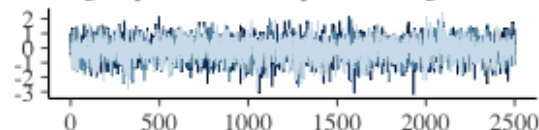

$-1$

$-2$

$-3$

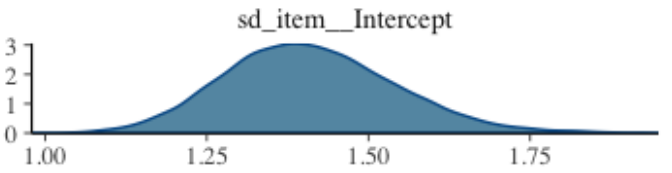

sd_item_Intercept

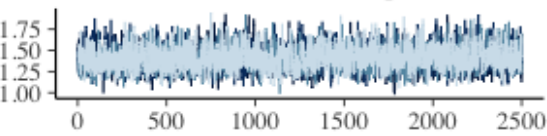

sd_item_groupcontrol

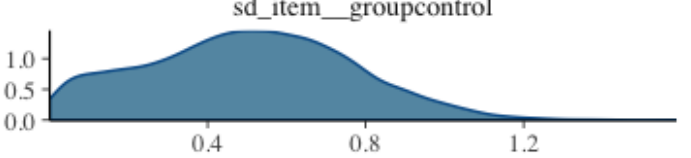

sd_item_groupcontrol
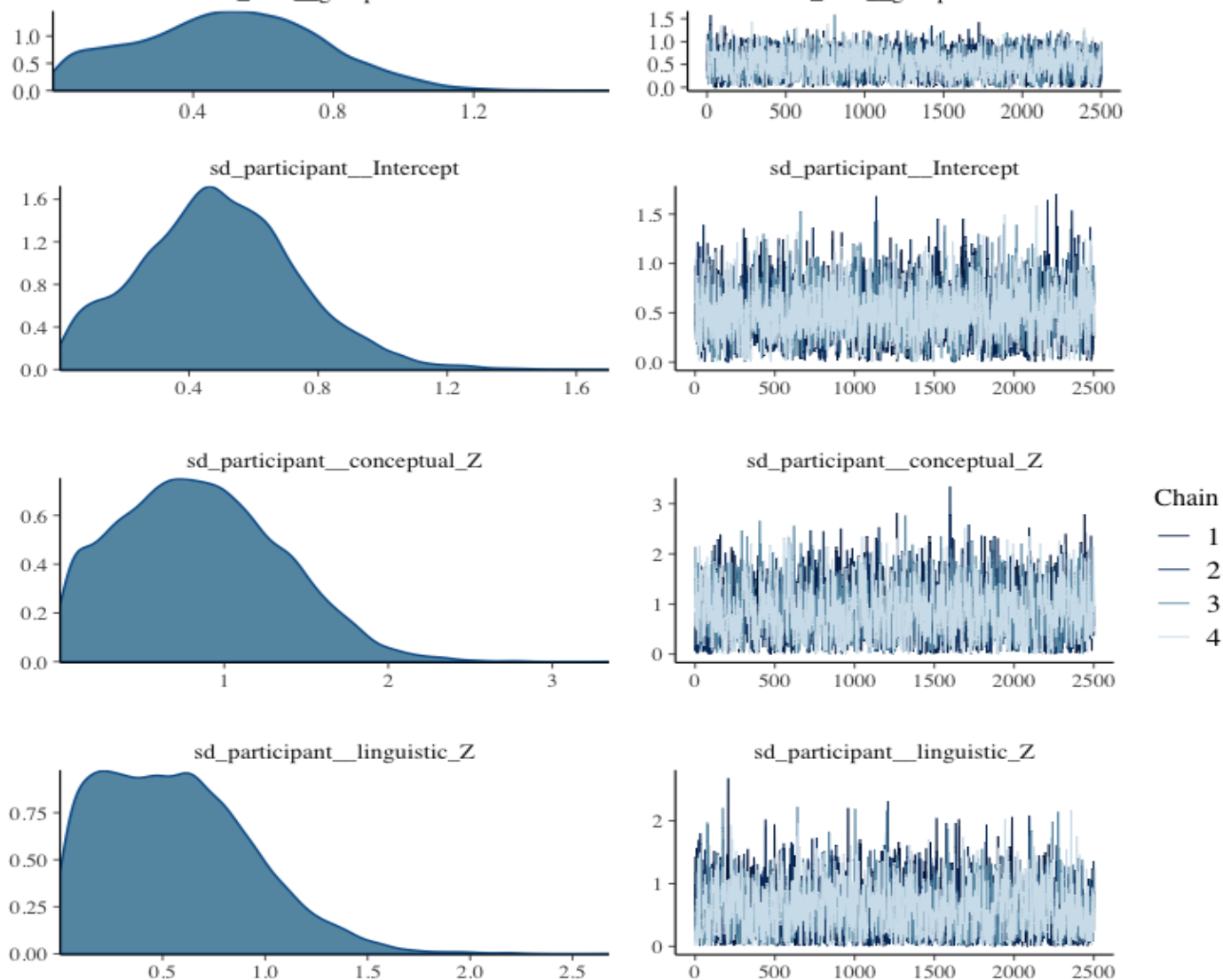


\section{A.2 Trace and density plots for MCMC samples for Model 2}
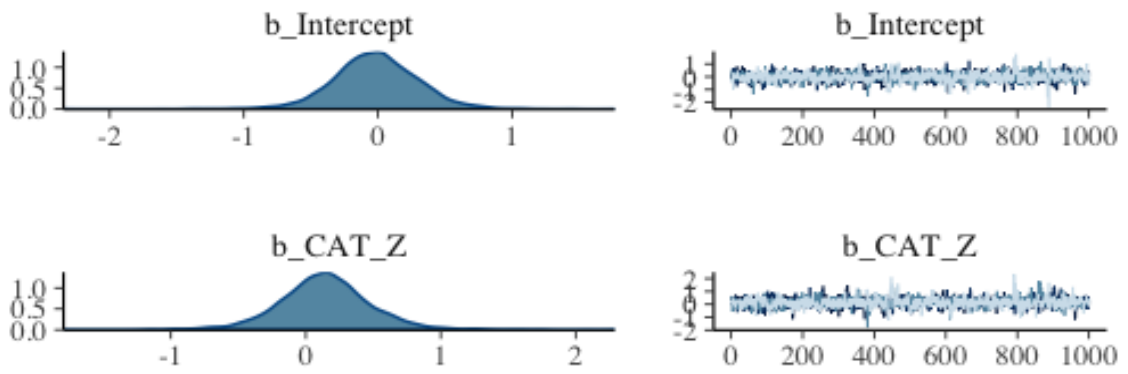

\section{b_CAT_Z}

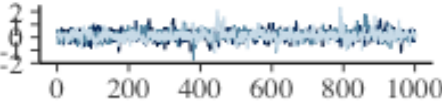
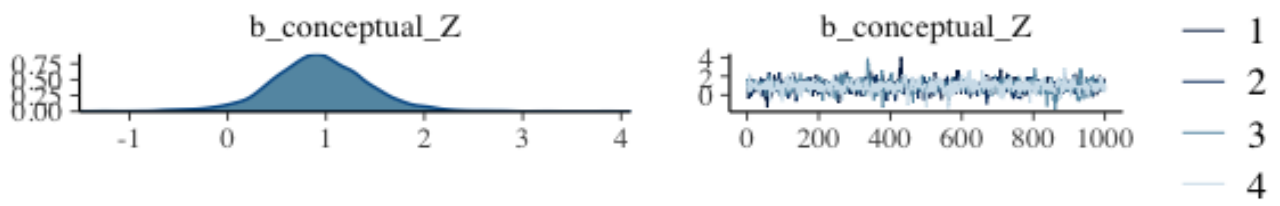

b_linguistic_Z

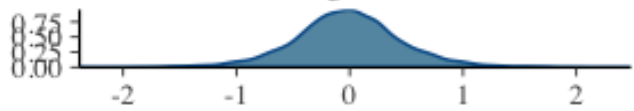

b_linguistic_Z

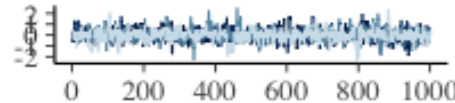

b_CAT_Z:conceptual_Z

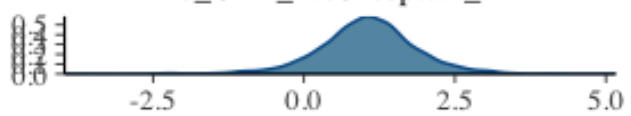

b_CAT_Z:conceptual_Z

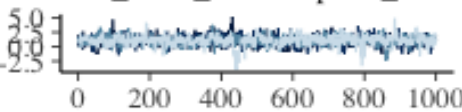

b_CAT_Z:linguistic_Z

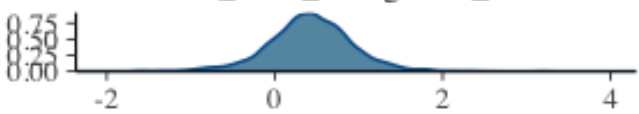

b_CAT_Z:linguistic_Z

$\begin{array}{llllll}4 & -1 \\ 0 & 200 & 400 & 600 & 800 & 1000\end{array}$

b_conceptual_Z:linguistic_Z

b_conceptual_Z:linguistic_Z

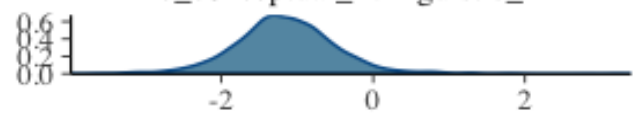

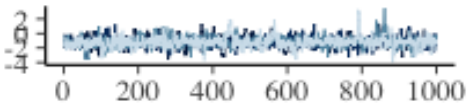

Chain

b_CAT_Z:conceptual_Z:linguistic_Z

XAT_Z:conceptual_Z:linguistic

$-1$

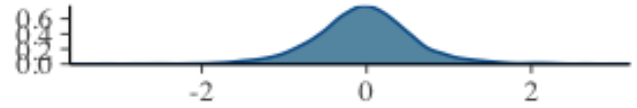

2 专

\begin{tabular}{llllll}
\hline & 200 & 400 & 600 & 800 & 1000
\end{tabular}$-3$
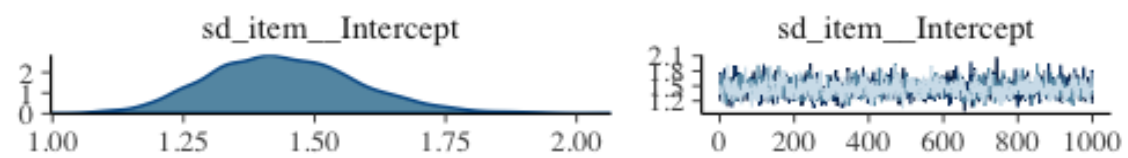

sd_item_CAT_Z

sd_item_CAT_Z
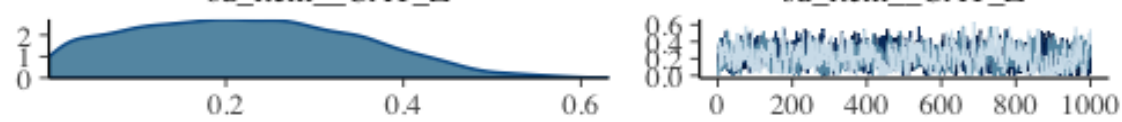

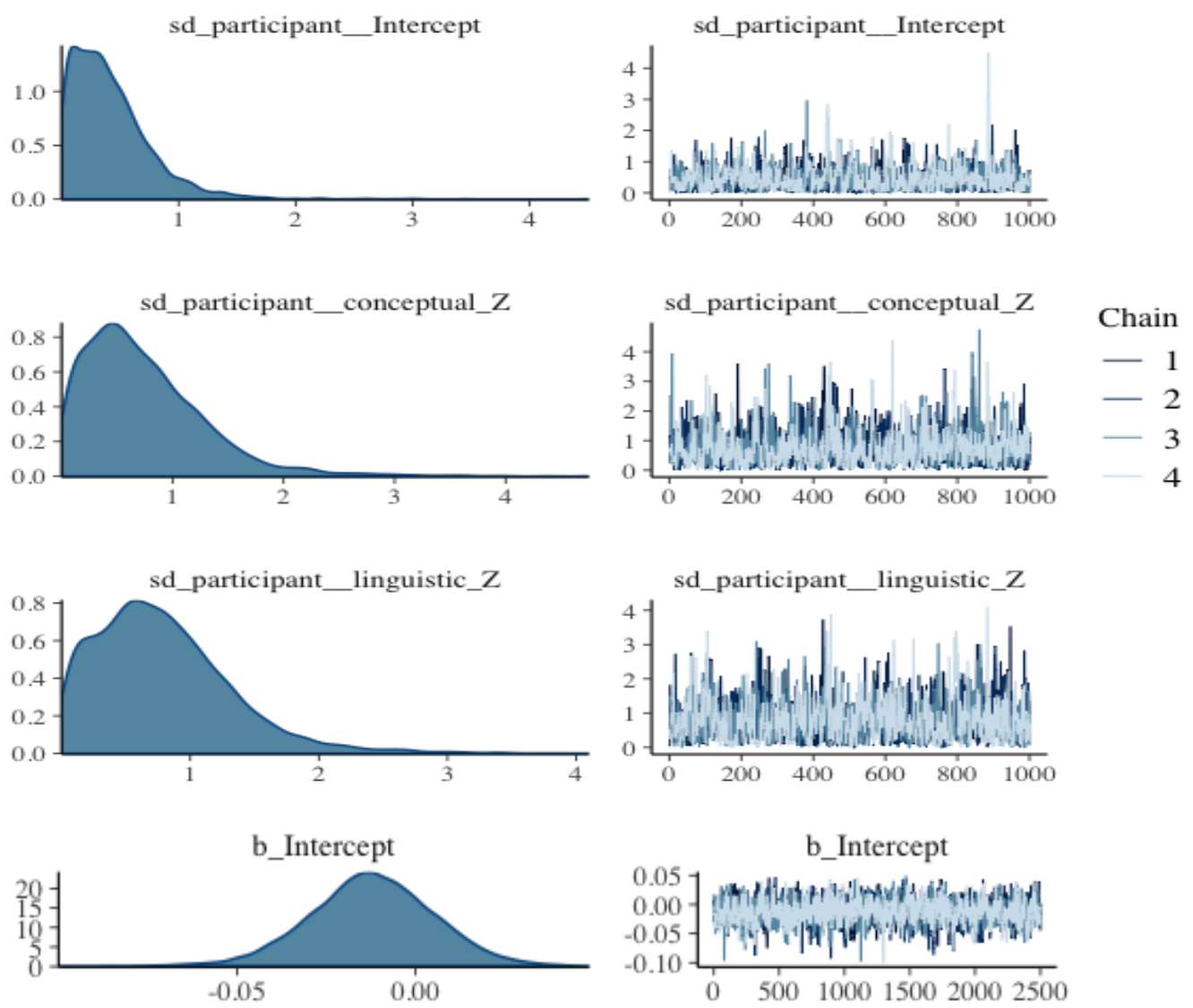

\section{b_CAT_Z}
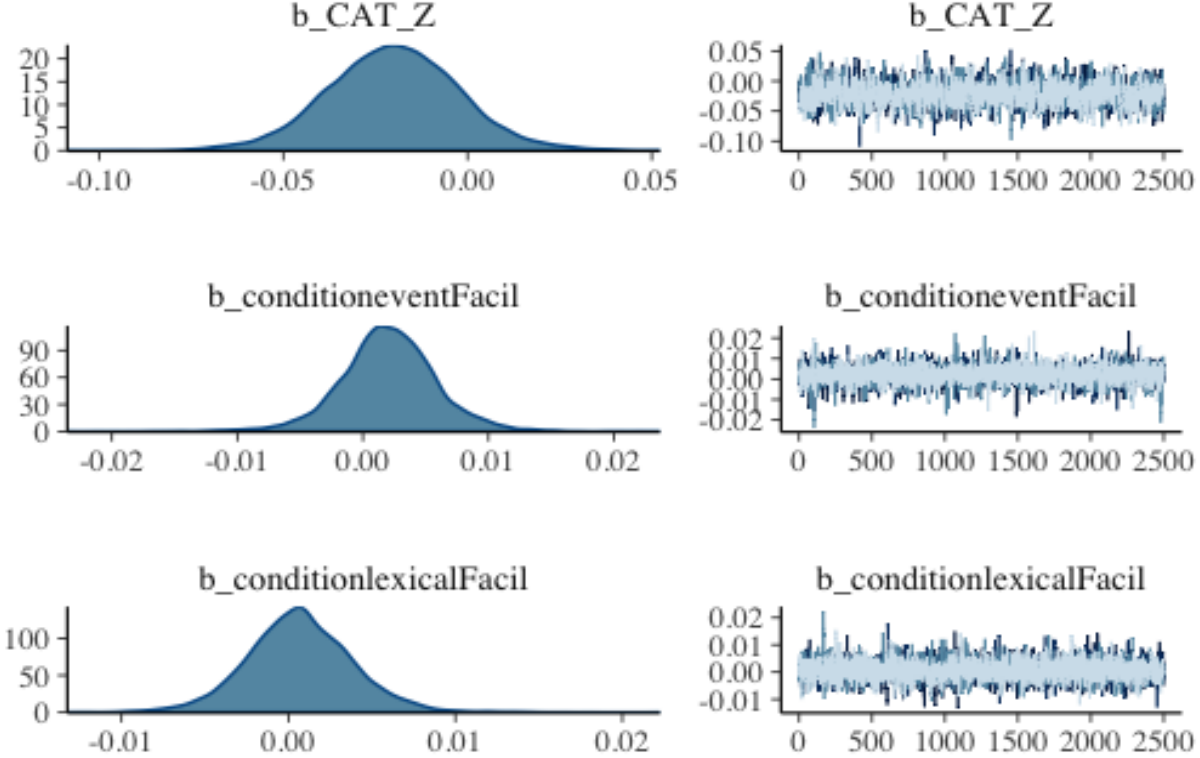

Chain

-1
$-\quad 2$
$-\quad 3$
$-\quad 4$

b_CAT_Z:conditioneventFacil

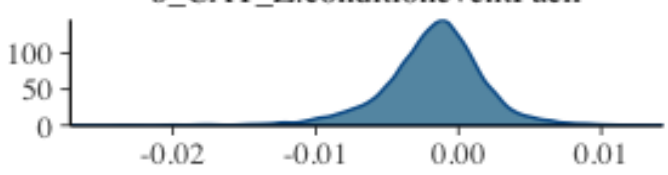

_CAT_Z:conditioneventFaci

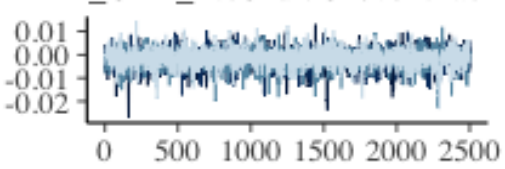


